\title{
Expression Profiling of Cellular MicroRNA in Asymptomatic HBsAg Carriers and Chronic Hepatitis B Patients
}

\author{
Xianliang Hou, Yan Liang, Jianing Chen, Yingfeng Wei, Ping Zeng, Lin Wang, \\ Chong Lu, and Hongyan Diao
}

State Key Laboratory for Diagnosis and Treatment of Infectious Diseases, Collaborative Innovation Center for Diagnosis and
Treatment of Infectious Diseases, The First Affiliated Hospital, College of Medicine, Zhejiang University, Hangzhou 310003, China

Correspondence should be addressed to Hongyan Diao; diao.hy@163.com

Received 22 January 2017; Revised 31 May 2017; Accepted 22 June 2017; Published 23 August 2017

Academic Editor: Stephen H. Safe

Copyright (c) 2017 Xianliang Hou et al. This is an open access article distributed under the Creative Commons Attribution License, which permits unrestricted use, distribution, and reproduction in any medium, provided the original work is properly cited.

Background. MicroRNAs (miRNAs) may serve as potential molecular markers to predict liver injury resulting from chronic hepatitis $\mathrm{B}(\mathrm{CHB})$. In the present study, we want to study the expression profile and clinical significance of miRNAs at different stages of $\mathrm{CHB}$ virus infection. Methods. Using miRNA microarray, we investigated the global expression profiles of cellular miRNA in asymptomatic hepatitis B antigen carriers (ASCs) and CHB patients, compared with healthy controls (HCs). Results. We identified 79 and 203 differentially expressed miRNAs in the peripheral blood mononuclear cells of ASCs and CHB patients compared to HCs, respectively. Some of these miRNAs were common to ASCs and CHB patients, but another set of miRNAs that showed differential expression between ASCs and CHB patients was also identified. Gene ontology and pathway enrichment analysis showed that the target genes of the identified miRNAs played a role in important biological functions, such as learning or memory, cell-cell adherens junction, ion channel inhibitor activity, TGF-beta signaling pathway, and p53 signaling pathway. Conclusion. We identified some significant differentially expressed miRNA in different phases of HBV infection, which might serve as biomarkers or therapeutic targets in the future.

\section{Introduction}

Hepatitis B virus (HBV) is a hepatotropic noncytopathic DNA virus that is a major cause of liver diseases [1]. Eradication of HBV infection remains a global health challenge. More than 350 million people worldwide are persistent carriers of $\mathrm{HBV}$, and many may progress to chronic liver disease. One to two million people die annually worldwide from HBVrelated disease [2], which results in an increase in healthcare cost and other socioeconomic burdens. In most adults, HBV infection is self-limiting and characterized by quick viral clearance; however, in some cases, the patients become carriers or develop chronic persistent infection. According to their serological profile [3], patients can be divided into two well-distinguished subsets of subjects: (1) asymptomatic HBV carriers (ASCs) and (2) chronic hepatitis B (CHB) patients. ASCs show long-lasting inhibition of viral replication with viral load levels that are usually below 2,000 IU/mL and no biochemical, ultrasonographic, or histological evidence of liver injury. On the contrary, anti-HBe-positive $\mathrm{CHB}$ patients have active liver disease with a high risk of progression toward cirrhosis [4]. The difference in the responses to HBV infection is probably related to the exclusive dependence of HBV on host cellular machinery for its propagation and survival. Therefore, investigation of the interactions between HBV and host cells is crucial for understanding viral pathogenesis and the development of new antiviral therapies.

MicroRNAs (miRNAs) are small noncoding RNA molecules that are about 22 nucleotides long and regulate gene expression by base pairing with the $3^{\prime}$-untranslated region of target mRNAs, which usually leads to mRNA degradation or translational silencing. miRNAs have been identified in most types of cells and tissues and are involved in a variety of biological processes, such as inflammation, cell proliferation, development, differentiation, apoptosis, and tumorigenesis. Further, miRNAs play vital roles in the pathogenesis of various diseases, such as cancers and viral infections, through posttranscriptional regulation of more 
than $30 \%$ of human genes [5]. Cellular miRNAs also affect virus replication and pathogenesis, as demonstrated in the case of the liver-specific miRNA miR-122, which is essential for the replication of hepatitis $C$ virus [6]. In addition, Zhang et al. found that the plasma miRNA profiles can indeed be used as a predictor of early virological response to interferon treatment in CHB patients [7]. In line with these findings, some reports suggest that circulating miRNAs may serve as potential molecular markers of liver injury resulting from CHB [8-10]. As the viral titer in the body, the degree of liver damage, and the immune characteristics vary between ASCs and CHBs, the expression profiles of miRNAs may also differ between these two groups of patients. However, there is not much information available about the relationships between cellular miRNAs and the different phases of chronic HBV infection. Therefore, the present study was conducted with the aim of filling in this gap in information.

Using miRNA microarray and PCR analysis, we investigated the global expression profiles of cellular miRNAs in peripheral blood mononuclear cells (PBMCs) from ASCs and $\mathrm{CHB}$ patients and identified a few novel miRNAs that were closely involved with the pathogenesis of HBV infection. Further, network analyses were used to determine the biological roles played by the target genes of these miRNAs in both ASCs and $\mathrm{CHB}$ patients.

\section{Material and Methods}

2.1. Clinical Samples. Human blood samples were obtained from healthy donors and patients with their informed consent. The study group included sixteen ASC patients, sixteen $\mathrm{CHB}$ patients, and sixteen healthy controls (HCs), who were recruited from the First Affiliated Hospital, College of Medicine, Zhejiang University, between 2014 and 2015. The study protocol conforms to the ethical guidelines of the 1975 Declaration of Helsinki, and all the patients provided their written informed consent for participation. The symptoms of all the patients were diagnosed according to the previously described criteria [11]. The level of HBs antigen was measured quantitatively using the Abbott chemiluminescence immunoassay kit (Abbott Japan, Tokyo, Japan). Quantitative detection of HBV DNA was performed using an ABI7300-type quantitative PCR instrument (Applied Biosystems, USA). The results are expressed as the number of $\log 10$ international units per milliliter.

2.2. Separation of PBMCs, RNA Extraction, and miRNA Microarray. Samples containing $5 \mathrm{ml}$ of blood were collected. PBMCs were isolated using standard density-gradient centrifugation on Ficoll-Paque (Amersham Biosciences, Freiburg, Germany). Total cellular RNA from the PBMCs was extracted using the TRIzol RNA reagent (Invitrogen, Carlsbad, CA, USA) according to the manufacturer's instructions. Low-molecular-weight RNA was isolated using the mirVana miRNA isolation kit (Ambion, Austin, TX, USA) [12]. We performed miRNA microarray analysis to identify HBVassociated differences in cellular miRNA profiles between three ASC patients and three CHB patients and three healthy controls. miRNA microarray analysis was performed using
TABLE 1: Primer sequence of quantitative RT-PCR.

\begin{tabular}{ll}
\hline Gene name & Primer sequence \\
\hline \multirow{2}{*}{ U6 } & F: \\
& 5'-GCTTCGGCAGCACATATACTAAAAT-3' \\
hsa-miR-195-3p & F: 5' 5'CCAATATTGGCTGTGCTGCTC-3' $^{\prime}$ \\
hsa-miR-144-5p & F: \\
& 5'-CGCGGATATCATCATATACTGTAAG-3' \\
hsa-miR-45la & F: 5'-CGAAACCGTTACCATTACTGAGTT-3' \\
hsa-miR-920 & F: 5'-GGGGAGCTGTGGAAGCAGT-3' \\
\hline
\end{tabular}

the miRMAX microarray at KangChen Bio-Tech Corporation (Shanghai, China) [13]. The arrays were scanned using an Axon GenePix 4000B microarray scanner, and GenePix pro V6.0 was used to read the raw intensity of the image. We used the median normalization method to obtain normalized data (normalized data $=[$ foreground value - background value]/median, where the median is the 50 percent quantile of microRNA intensity, which was greater than 30 in all the samples after background correction). An miRNA was considered to be differentially expressed if the difference in its expression was more than 2.0-fold.

2.3. Quantitative Real-Time PCR for miRNA Verification. The quantitative PCR validation group consisted of $16 \mathrm{CHB}$ patients, 16 ASC patients, and 16 healthy controls. Four differentially expressed miRNA were randomly selected for verification. Expression of these mature miRNAs was assayed using the Mir-X miRNA First-Strand Synthesis Kit (number 638313, Clontech Laboratories, Inc.) and SYBR Premix Ex Taq II (Tli RNase H Plus) kit (number RR820A, Takara Bio, Inc.). Briefly, in the Mir-X cDNA synthesis reaction, RNAs are poly (A)-tailed using poly(A) polymerase and then copied using a modified oligo(dT) primer and SMART MMLV Reverse Transcriptase. The reaction mixture contained $5 \mu \mathrm{l}$ of $2 \times$ mRQ Buffer, 3.75 ul RNA sample (0.25-8 ug), and $1.25 \mathrm{ul}$ mRQ Enzyme. The reaction was performed as follows: 1 hour at $37^{\circ} \mathrm{C}$ and then terminate at $85^{\circ} \mathrm{C}$ for $5 \mathrm{~min}$ to inactivate the enzymes. These synthetic cDNA were then specifically and quantitatively amplified using a miRNA-specific primer and SYBR advantage qPCR chemistry. All the primers for quantitative PCR (shown in Table 1) were synthesized by Sangon Biotech (Shanghai) Co., Ltd. The reaction mixture contained $5 \mu \mathrm{l}$ of $2 \times$ SYBR Premix Ex Taq II (Tli RNase H Plus), $0.2 \mathrm{ul} \mathrm{miRNA-specific} \mathrm{primer} \mathrm{(} 20 \mathrm{uM}), 0.2 \mathrm{ul} \mathrm{mRQ}$ $3^{\prime}$ primer, $0.2 \mathrm{ul} \mathrm{ROX}$ Reference Dye (50X), and nucleasefree water, which made a total volume of $8 \mu \mathrm{l}$. Each $8 \mu \mathrm{l}$ mixture was added to a well in a 384-well PCR plate, and this was followed by addition of $2 \mu \mathrm{l}$ cDNA in each hole. The reaction conditions were as follows: $95^{\circ} \mathrm{C}$ for $2 \mathrm{~min}$ followed by 40 cycles of $95^{\circ} \mathrm{C}$ for $15 \mathrm{~s}$ and $60^{\circ} \mathrm{C}$ for $45 \mathrm{~s}$ [14]. The relative amount of miRNA was normalized against an internal control, U6 snRNA, and the fold change in the amount of each miRNA was calculated using the $2^{-\Delta \Delta C T}$ method. 
TABLE 2: Clinical data of patients used for cellular miRNA analysis.

\begin{tabular}{|c|c|c|c|c|}
\hline Clinical characteristics & $\mathrm{HC}$ & ASC & $\mathrm{CHB}$ & $P$ value \\
\hline Number of patients & 16 & 16 & 16 & $P=\mathrm{NS}$ \\
\hline \multicolumn{5}{|l|}{ Sex number (\%) } \\
\hline Female & 6 & 5 & 6 & \\
\hline Male & 10 & 11 & 10 & $P=\mathrm{NS}$ \\
\hline \multicolumn{5}{|l|}{ Age (years) } \\
\hline Median & 45 & 43 & 42 & \\
\hline Range & $34-65$ & $27-64$ & $25-62$ & $P=\mathrm{NS}$ \\
\hline ALT & & & & $P=$ NS $($ ASC versus HC $)$ \\
\hline Median & 27.43 & 34.38 & 95.36 & $P<0.001(\mathrm{CHB}$ versus $\mathrm{HC})$ \\
\hline Range & $9-69$ & $17-89$ & $16-253$ & $P<0.001$ (CHB versus ASC) \\
\hline AST & & & & $P=$ NS $($ ASC versus HC) \\
\hline Median & 24 & 35.29 & 75.50 & $P=0.028(\mathrm{CHB}$ versus $\mathrm{HC})$ \\
\hline Range & $14-34$ & $21-84$ & $9-327$ & $P=\mathrm{NS}(\mathrm{CHB}$ versus $\mathrm{ASC})$ \\
\hline \multicolumn{5}{|l|}{ HBV DNA } \\
\hline Median & NA & $1.51 \times 10^{6}$ & $2.70 \times 10^{8}$ & \\
\hline Range & NA & $2.12 \times 10^{3}-5.99 \times 10^{6}$ & $2.37 \times 10^{4}-2.51 \times 10^{9}$ & $P=\mathrm{NS}(\mathrm{CHB}$ versus ASC $)$ \\
\hline \multicolumn{5}{|l|}{ HBsAg } \\
\hline HBsAg $(+)$ & NA & $4(25 \%)$ & $10(62.5 \%)$ & \\
\hline HBsAg $(-)$ & NA & $12(75 \%)$ & $6(37.5 \%)$ & $P=0.033(\mathrm{CHB}$ versus $\mathrm{ASC})$ \\
\hline
\end{tabular}

2.4. Gene Ontology Analysis and Signaling Pathway Analysis. Target genes of the differentially expressed miRNAs were predicted based on agreement between the two databases to predict miRNAs' target genes: targetscan7.1 and mirdbV5. Signaling pathway analysis and gene ontology (GO) analysis were performed to determine the biological functions of the target genes of differentially expressed miRNAs. The genes were mapped to each node in the GO database, and the number of genes in each node was calculated. Signaling pathway analysis is a functional analysis for mapping genes to KEGG pathways. GenMAPP v2.1 was used to map the genes to the KEGG database through the signaling pathway, and then statistical analysis was performed to determine the degree of enrichment of the genes in each pathway [15].

2.5. Statistical Analysis. Data analysis was performed using SPSS 19. Data were expressed as the mean \pm standard deviation values. The statistical significance of differences between two groups was analyzed by the $t$-test.

\section{Results}

3.1. Patient Characteristics. The clinical characteristics of the patients according to group are shown in Table 2 . The mean age and male:female ratio were similar between the three groups. The distribution of ALT and AST was not found to be different between ASC group and HC group, but it is significantly increased in CHB group compared with ASC group and $\mathrm{HC}$ group. The average amounts of HBV DNA were higher in CHB than in ASC, but there was no significant difference. The prevalence of hepatitis B surface antigen
(HBsAg) was $62.5 \%$ in $\mathrm{CHB}$ and $25 \%$ in ASC. There was significant difference between them $(P=0.033)$.

3.2. miRNA Expression by Microarray Analysis. Among the 2077 human mature miRNAs investigated by the arrays, 79 miRNAs were found to be differentially expressed ( $>2$-fold) between the ASC group and HC group, which accounted for $3.80 \%$ of all the miRNAs investigated. Of these, 11 were upregulated and 68 were downregulated in the ASC group. In addition, 203 miRNAs (9.77\%) were differentially expressed ( $>2$-fold) between the $\mathrm{CHB}$ group and $\mathrm{HC}$ group, including 118 upregulated miRNAs and 85 downregulated miRNAs in the CHB group. Further, 144 (6.93\%) miRNAs exhibited more than a 2-fold difference in expression between the CHB group and the ASC group, of which 115 miRNAs were upregulated and 29 were downregulated. Among the differentially expressed miRNAs, 38 miRNAs were common to both the ASC group and CHB group, 5 of which were upregulated and 33 of which were downregulated in both groups (Table 3 ).

3.3. Validation of the Microarray Results by Quantitative Real-Time PCR. Four miRNAs with abnormal expression, namely, hsa-miR-195-3p, hsa-miR-144-5p, hsa-miR-451a, and hsa-miR-920, were selected and analyzed by real-time quantitative PCR in order to validate the microarray results. Consistent with the array data, the expression of these miRNAs was either upregulated or downregulated in the ASC group and $\mathrm{CHB}$ group in comparison with the $\mathrm{HC}$ group (Figure 1). The expression levels of hsa-miR-920 and hsamiR-195-3p still exhibited more than a 1.5 -fold increase in 
TABLE 3: Common miRNAs differentially expressed between ASC group and CHB group.

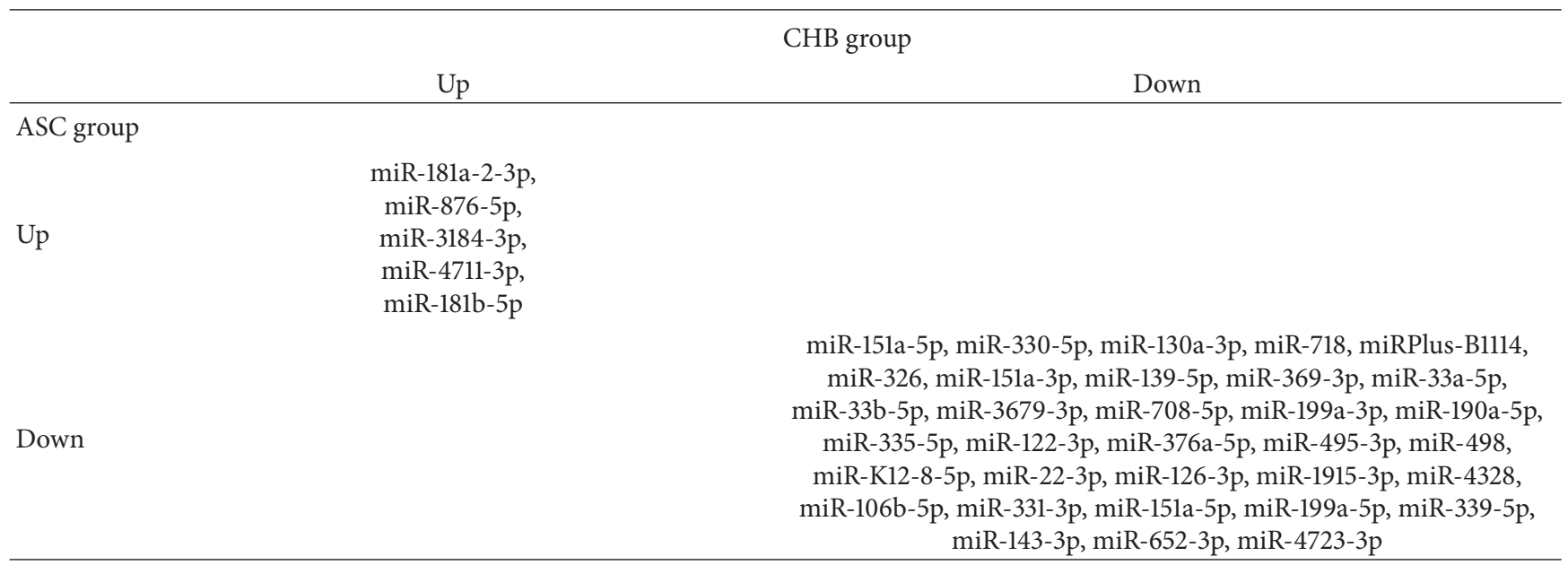
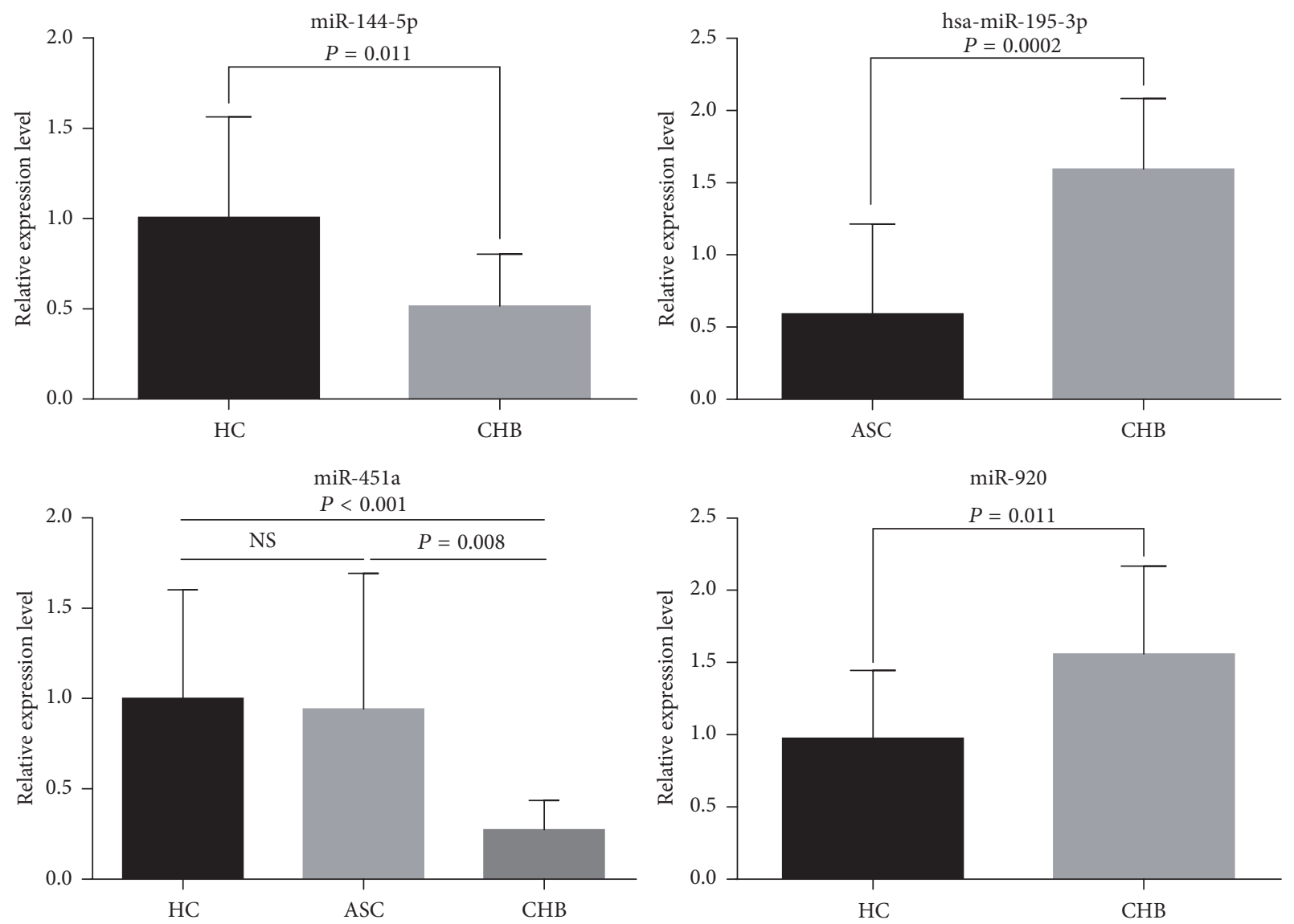

FIGURE 1: Validation of the microarray data by qRT-PCR analysis. Changes in the expression of the four randomly selected miRNAs showed good agreement between the RT-PCR and microarray results.

the CHB group when compared to the HC or ASC group $(P<0.05)$. Furthermore, the expression of hsa-miR-144-5p was still significantly downregulated in the CHB group, with around 2 -fold difference $(P<0.05)$. The expression of hsamiR-45la was similar between the HC and ASC groups, but it was significantly higher in the $\mathrm{CHB}$ group $(P<0.001$ and $P=0.008$, resp.).

3.4. Correlation of Four miRNAs with Clinical Indicators of ASC or CHB Patients. To investigate whether cellular 


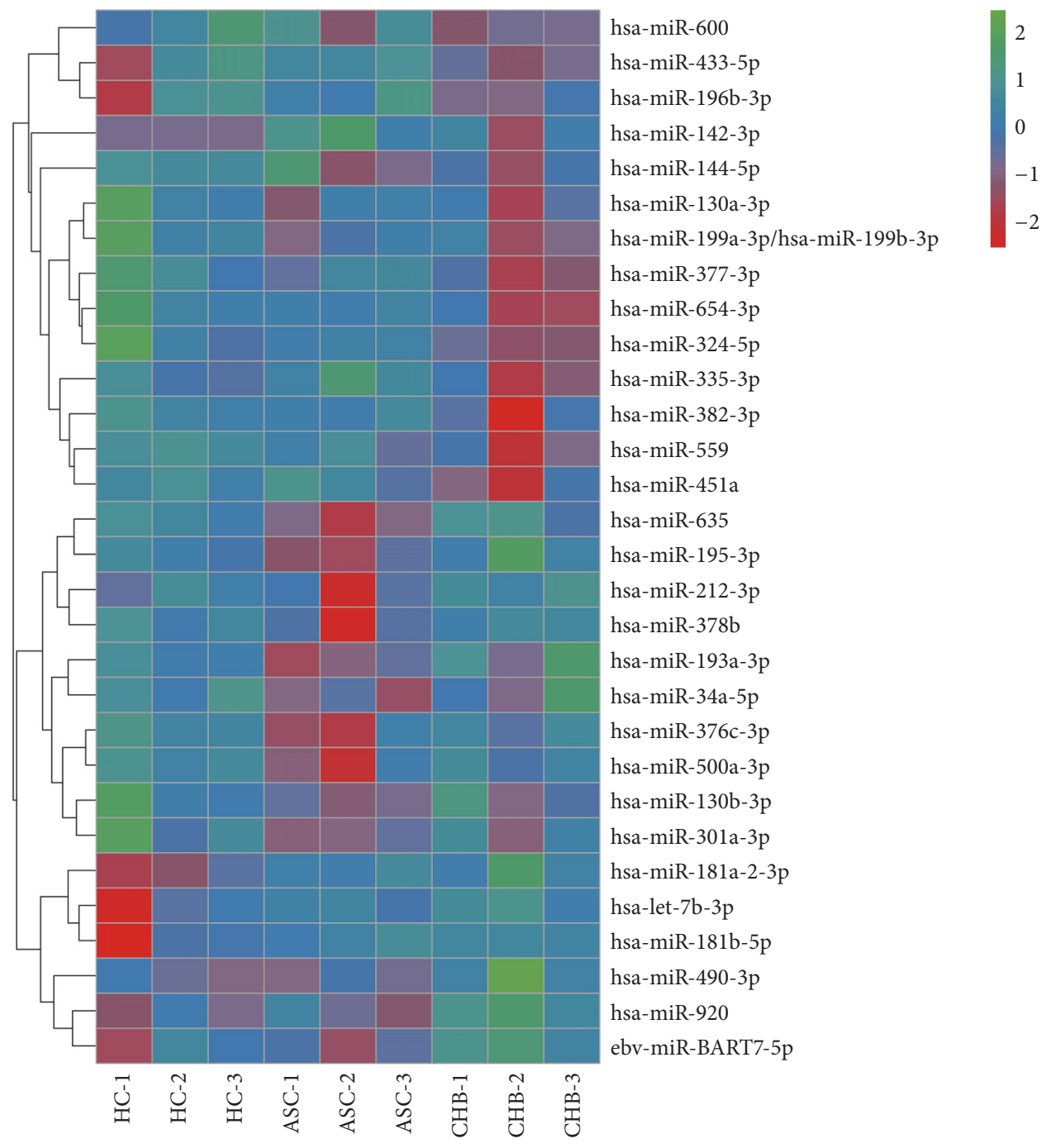

FIGURE 2: Hierarchical cluster analysis of the differentially expressed miRNAs. The red boxes represent upregulation of the corresponding miRNA, and the green boxes represent downregulation of the corresponding miRNA.

miR-195-3p, miR-144-5p, miR-451a, and miR-920 were related to $\mathrm{HBV}$ infection, we correlated these four miRNAs' expression level with clinical indicators of HBV infection including serum ALT level, HBsAg level, and HBV DNA level. However, no significant correlation was found. Although the levels of miR-144-5p and miR-451a were slight negatively correlated with ALT $(r=-0.329,-0.270 ; P=$ $0.135,0.135)$, the difference was statistically insignificant.

\subsection{GO Analysis of the Target Genes of the Differentially} Expressed miRNAs. The sample size was rather small, and there were individual differences within each group. Therefore, some false positive results were obtained, as some miRNAs showed abnormally high or low expression only in certain samples. Therefore, we screened more valuable miRNAs for target gene prediction, GO analysis, or signaling pathway analysis (Table 4). Hierarchical cluster analysis was performed to analyze the remaining data (Figure 2). The target sites were predicted using targetscan7.1 and mirdbV5.
The final target genes were those that were predicted by all the three miRNA prediction tools. miRNA-gene networks (Figure 3) based on the regulatory relationships between the miRNAs and their target genes were built. A total of 150 target genes were predicted for the differentially expressed miRNAs between the ASC and HC group; 119 genes, for the differentially expressed miRNAs between the $\mathrm{CHB}$ and HC group; and 36 genes, for the differentially expressed miRNAs between the CHB and ASC group. GO analysis consists of three components, namely, biological processes, cellular components, and molecular functions. The ten most commonly observed terms in each component were plotted to compare their differences between each group (Figure 4). The predicted target genes of the miRNAs that were differentially expressed in the ASC and CHB groups compared to the $\mathrm{HC}$ group were primarily involved with response to nutrient, regulation of primary metabolic process, cell part, kinase activity, and binding. Moreover, the predicted target genes of the miRNAs that were differentially expressed 
6

BioMed Research International
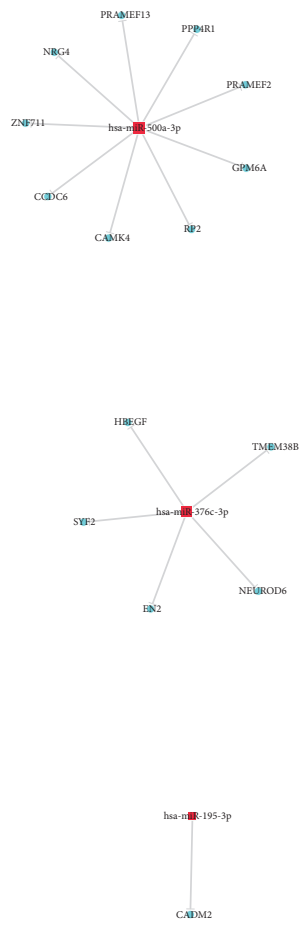
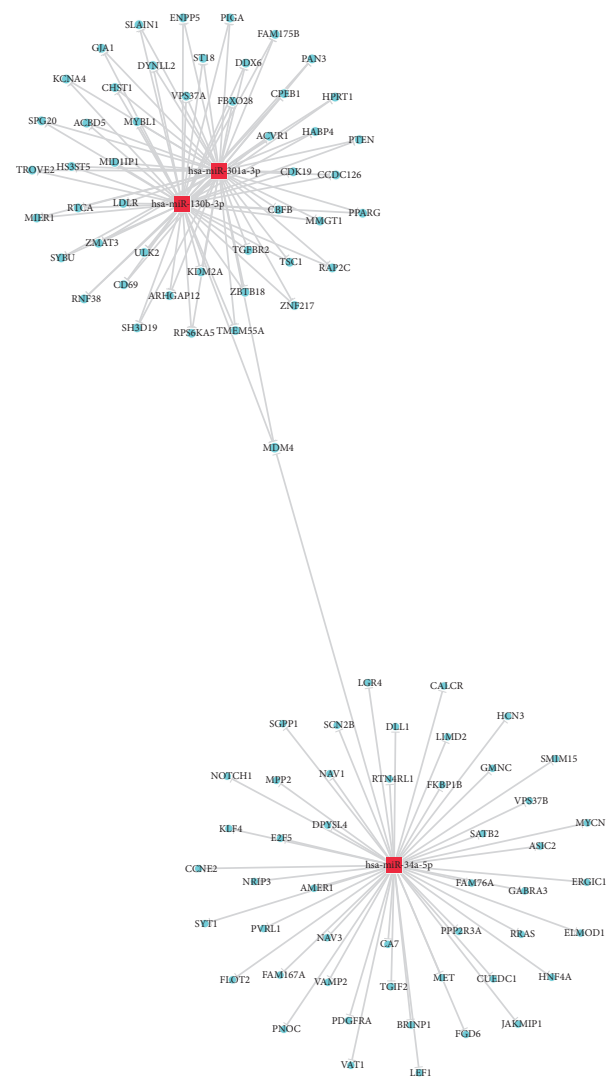

(a)
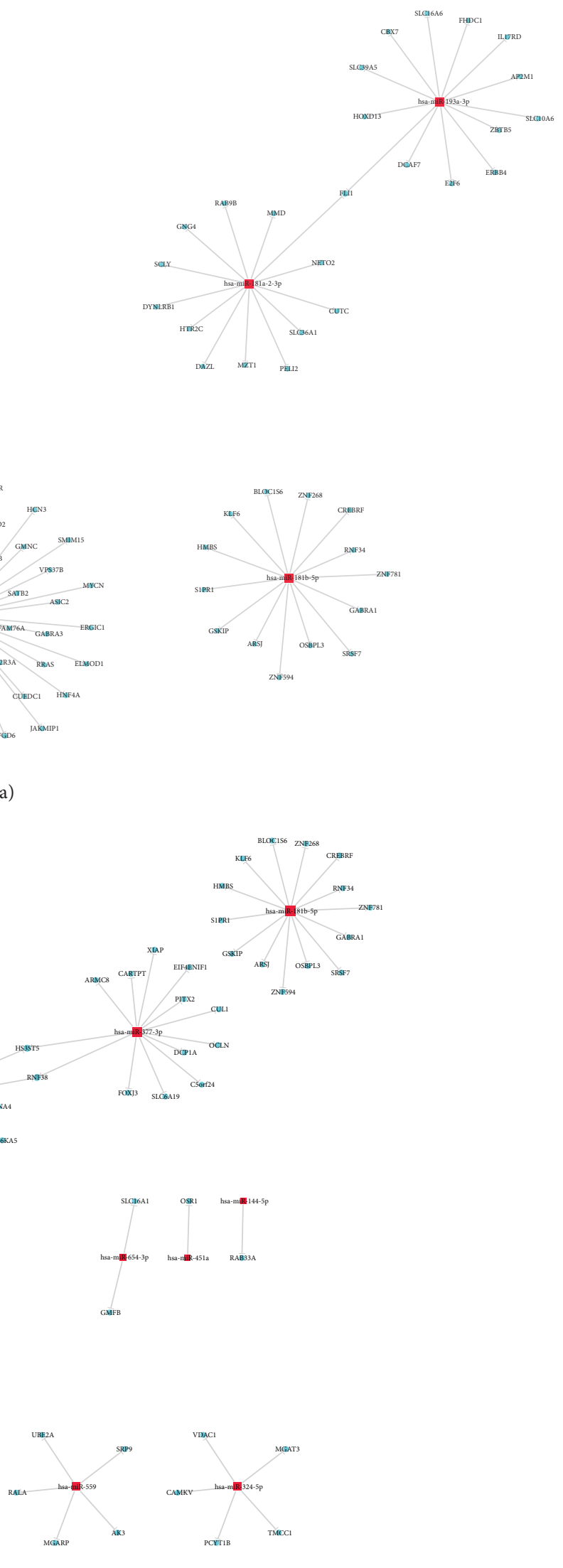

(b)

Figure 3: Continued. 


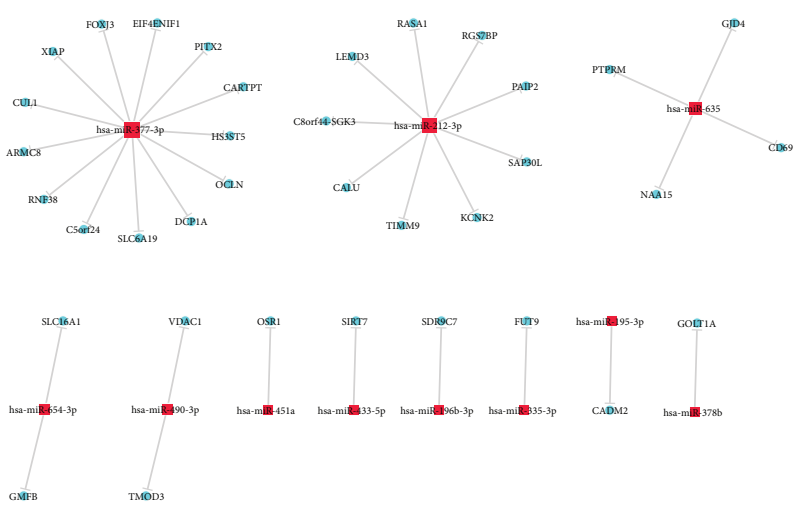

(c)

FIGURE 3: miRNA-gene networks built using the target genes of the differentially expressed miRNAs between the ASC group and HC group (a), CHB group and HC group (b), and CHB group and ASC group (c). The red squares represent miRNAs, and the blue round spots represent genes. The lines represent the interactions between miRNAs and genes.

TABLE 4: Significant differentially expressed miRNA in each group.

\begin{tabular}{|c|c|c|c|}
\hline & ASC versus HC & $\mathrm{CHB}$ versus $\mathrm{HC}$ & CHB versus ASC \\
\hline Upregulation & $\begin{array}{l}\text { hsa-miR-181a-2-3p, } \\
\text { hsa-miR-142-3p } \\
\text { hsa-miR-181b-5p }\end{array}$ & $\begin{array}{l}\text { hsa-miR-181a-2-3p } \\
\text { hsa-miR-920 } \\
\text { hsa-let-7b-3p } \\
\text { hsa-miR-181b-5p }\end{array}$ & $\begin{array}{c}\text { hsa-miR-490-3p } \\
\text { hsa-miR-212-3p } \\
\text { hsa-miR-635 } \\
\text { ebv-miR-BART7-5p } \\
\text { hsa-miR-195-3p } \\
\text { hsa-miR-378b }\end{array}$ \\
\hline Downregulation & $\begin{array}{l}\text { hsa-miR-376c-3p } \\
\text { hsa-miR-199a-3p } \\
\text { hsa-miR-130b-3p } \\
\text { hsa-miR-193a-3p } \\
\text { hsa-miR-195-3p } \\
\text { hsa-miR-500a-3p } \\
\text { hsa-miR-34a-5p } \\
\text { hsa-miR-301a-3p }\end{array}$ & $\begin{array}{l}\text { hsa-miR-130a-3p } \\
\text { hsa-miR-382-3p } \\
\text { hsa-miR-559 } \\
\text { hsa-miR-377-3p } \\
\text { hsa-miR-654-3p } \\
\text { hsa-miR-45la } \\
\text { hsa-miR-600 } \\
\text { hsa-miR-144-5p } \\
\text { hsa-miR-324-5p }\end{array}$ & $\begin{array}{l}\text { hsa-miR-335-3p } \\
\text { hsa-miR-433-5p } \\
\text { hsa-miR-377-3p } \\
\text { hsa-miR-654-3p } \\
\text { hsa-miR-45la } \\
\text { hsa-miR-196b-3p }\end{array}$ \\
\hline
\end{tabular}

between the $\mathrm{CHB}$ group and ASC group were involved with learning or memory, cell-cell adherens junction, and ion channel inhibitor activity. Pathway enrichment analysis was performed to further understand the functions and signal pathways of these predicted gene targets (Figure 5). The results indicated that the target genes of differentially expressed miRNAs between the ASC group and HC group were related to 26 signaling pathways, particularly the pathways associated with endocytosis, thyroid cancer, and p53 signaling pathway. Further, the target genes of the differentially expressed miRNAs between the CHB group and HC group played a role in 12 signaling pathways, primarily the TGF-beta signaling pathway, p53 signaling pathway, and RNA degradation. Finally, the target genes of the differentially expressed miRNAs between the ASC group and CHB group were related to 4 signaling pathways that were primarily involved with TGF-beta, ubiquitin mediated proteolysis, and cell adhesion molecules (CAMs).
3.6. miRNA-GO/Pathway Network Analysis. To better understand the associations between the differentially expressed miRNAs and the results of GO and signaling pathway analyses, miRNA-GO networks (Figure 6) and miRNA-pathway networks (Figure 7) were built. Differentially expressed miRNAs, the GO terms that their target genes were linked to, and the pathways they were involved in according to the pathway enrichment analysis are represented as nodes in the graph, and the biological relationship between two nodes is represented as a line. All lines were supported by at least one study from the published literature, a textbook, or functional information in the GO or KEGG database. Based on the lines, we could then infer the key roles of the relationships depicted in the networks. The degree of complexity of each node was of primary concern, because the weight (importance) of the regulator (in this case, the miRNA) increases as the degree of complexity increases, according to the theory of network biology [24]. The visualized networks indicated that 


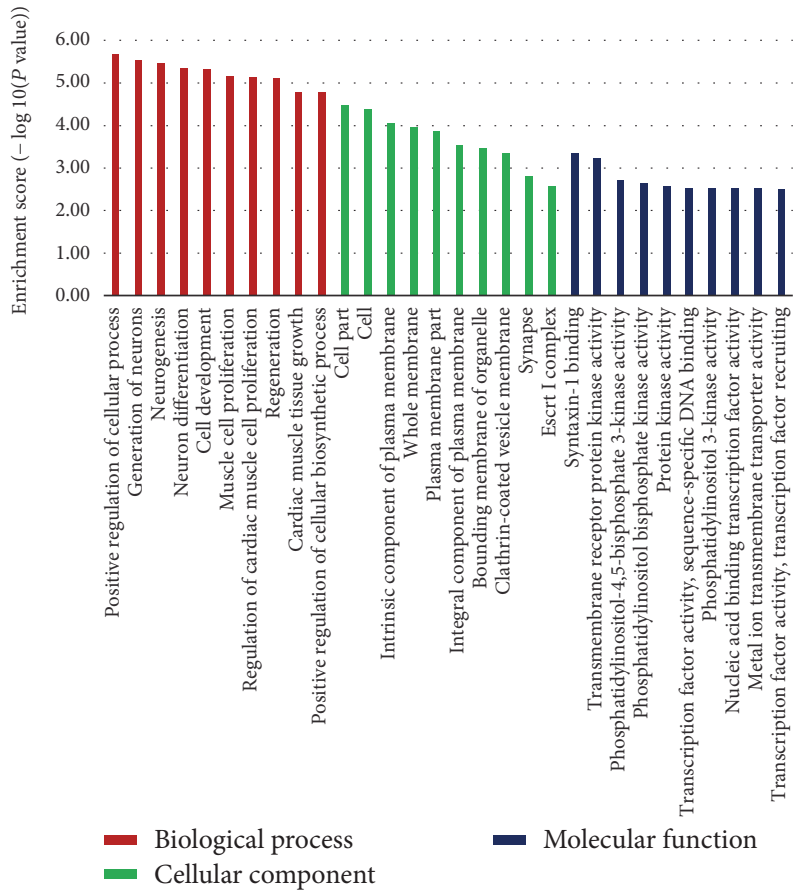

(a)

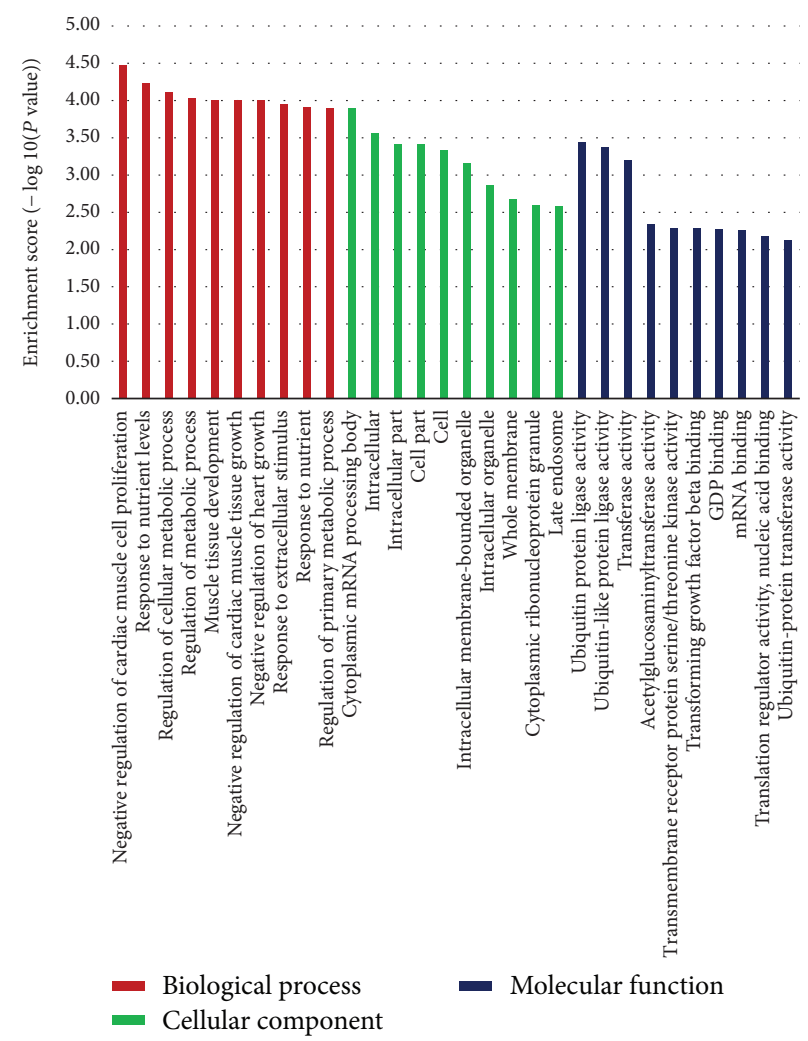

(b)

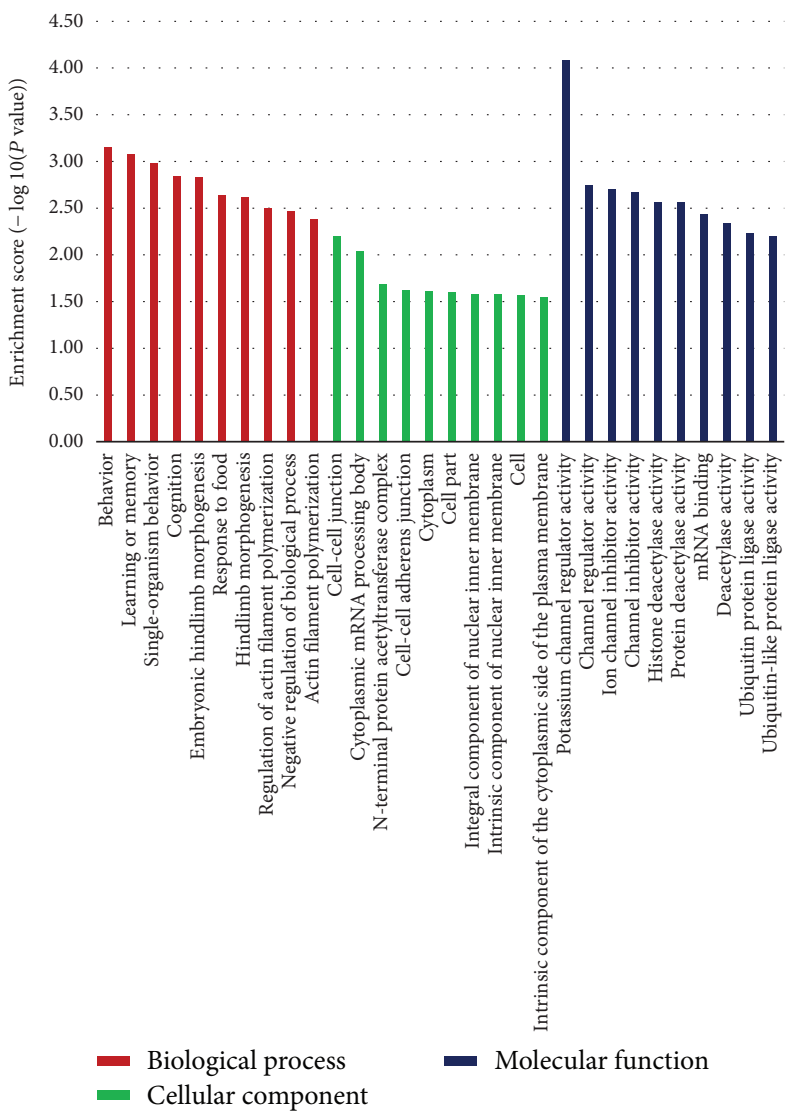

(c)

FIGURE 4: Functional classification of the target genes of differentially expressed miRNAs between the ASC group and HC group (a), CHB group and HC group (b), and CHB group and ASC group (c). 


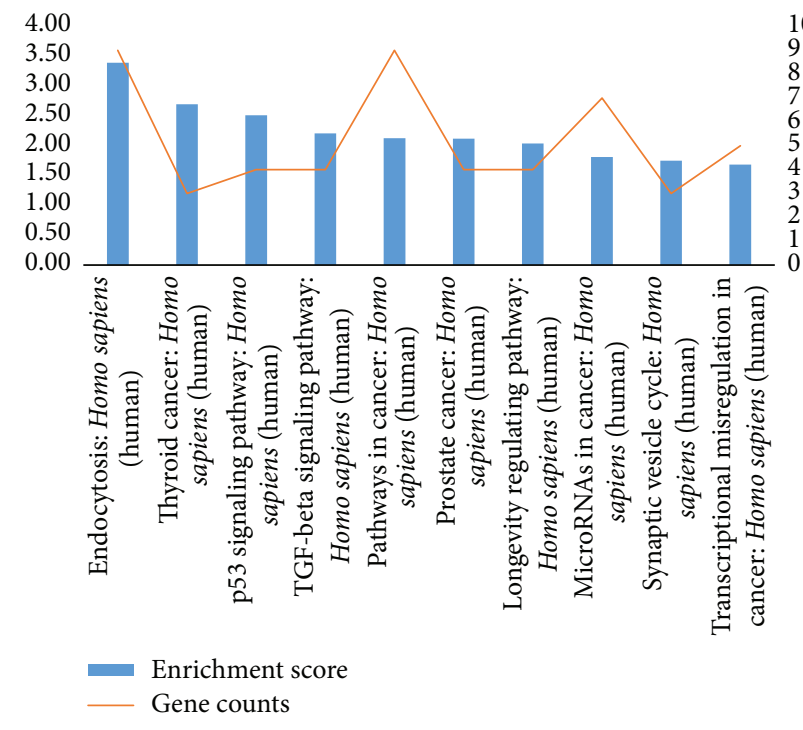

(a)

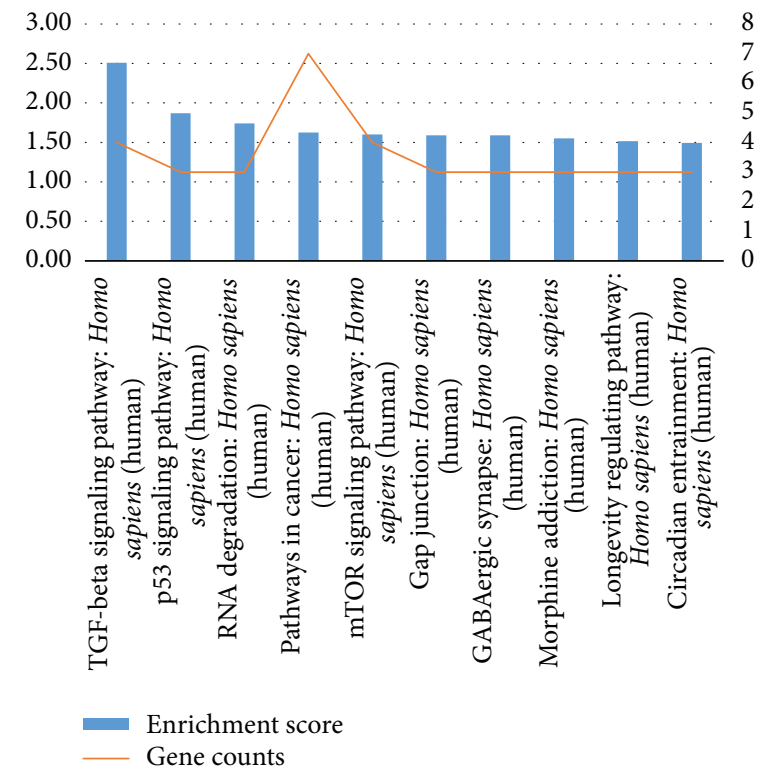

(b)

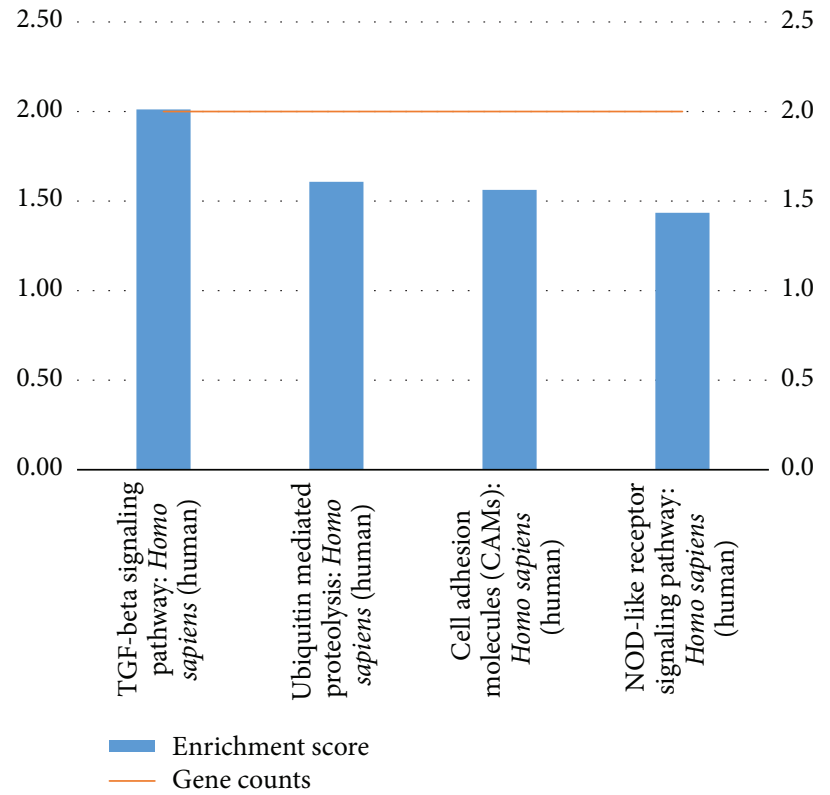

(c)

Figure 5: Pathway enrichment analysis of the target genes of differentially expressed miRNAs between the ASC group and HC group (a), CHB group and HC group (b), and CHB group and ASC group (c).

miR-142-3p, miR-181b-5p, miR-199a-3p, miR-130b-3p, miR$34 a-5 p$, miR-301a-3p, and miR-376c-3p played regulatory roles in modulating the molecular networks in ASCs. Further, the networks demonstrated that miR-181b-5p, miR-130a3p, miR-559, miR-920, miR-377-3p, miR-654-3p, miR-45la, miR-600, and miR-324-5p might be crucial regulators of pathogenesis in $\mathrm{CHB}$ patients. Finally, it was shown that miR-212-3p, miR-490-3p, miR-635, miR-377-3p, miR-654$3 \mathrm{p}$, and miR-45la played a prominent role in the global signaling networks and pathways involved in the progression of chronic liver disease, as these miRNAs carried considerable weight in both the ASC and CHB groups.

\section{Discussion}

In this report, utilizing miRNA array, we analyzed the global miRNA expression profiles in the PBMCs of healthy control individuals and $\mathrm{HBV}$-infected patients who were asymptomatic carriers or had chronic hepatitis B infection. Bioinformatics analysis of the microarray results revealed a set of miRNAs that were differentially expressed in the PBMCs of ASCs and CHB patients compared to the HCs. In addition, a significant number of the differentially expressed miRNAs were found in both ASCs and $\mathrm{CHB}$ patients. Moreover, we found that $144 \mathrm{mRNAs}$ exhibited more than a 


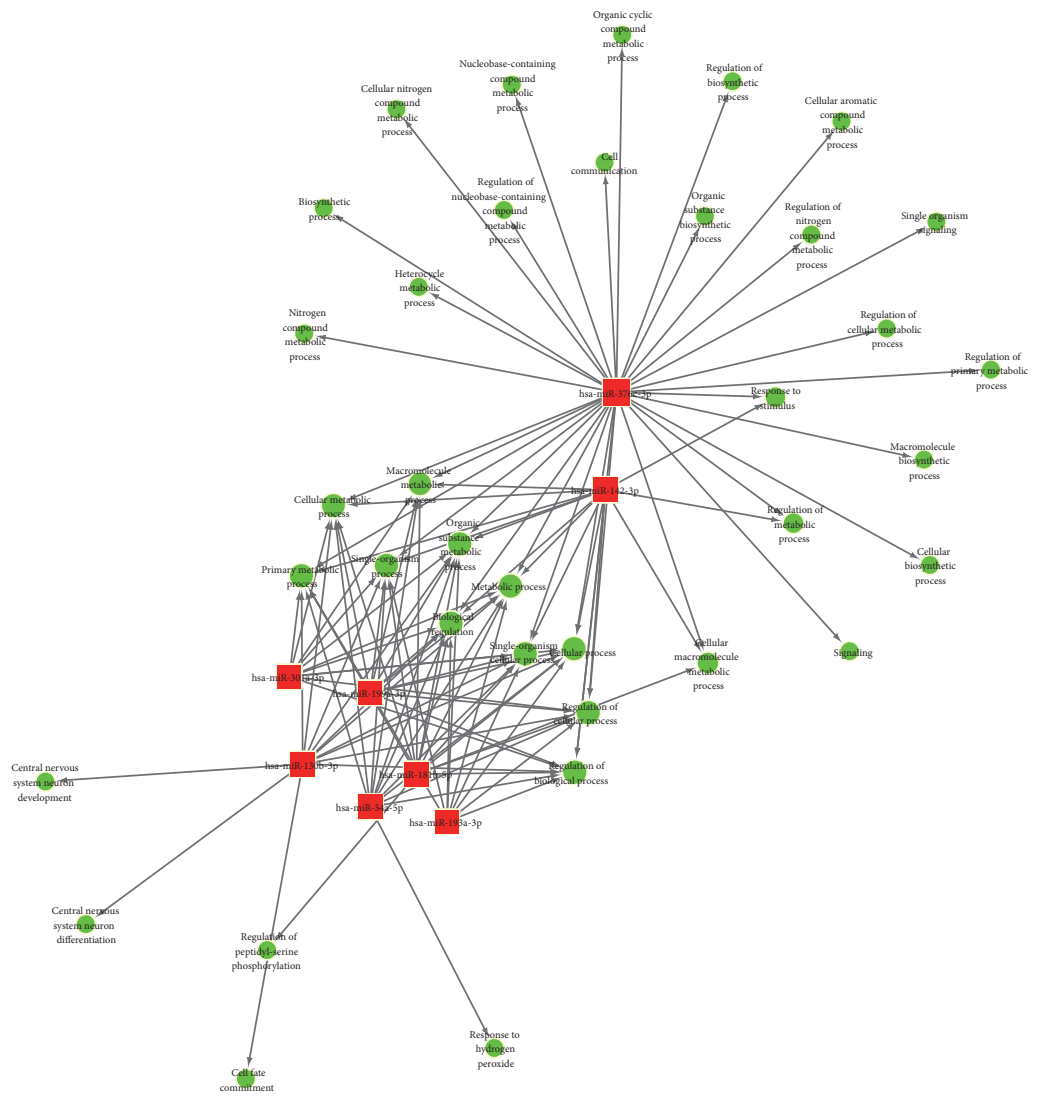

(a)

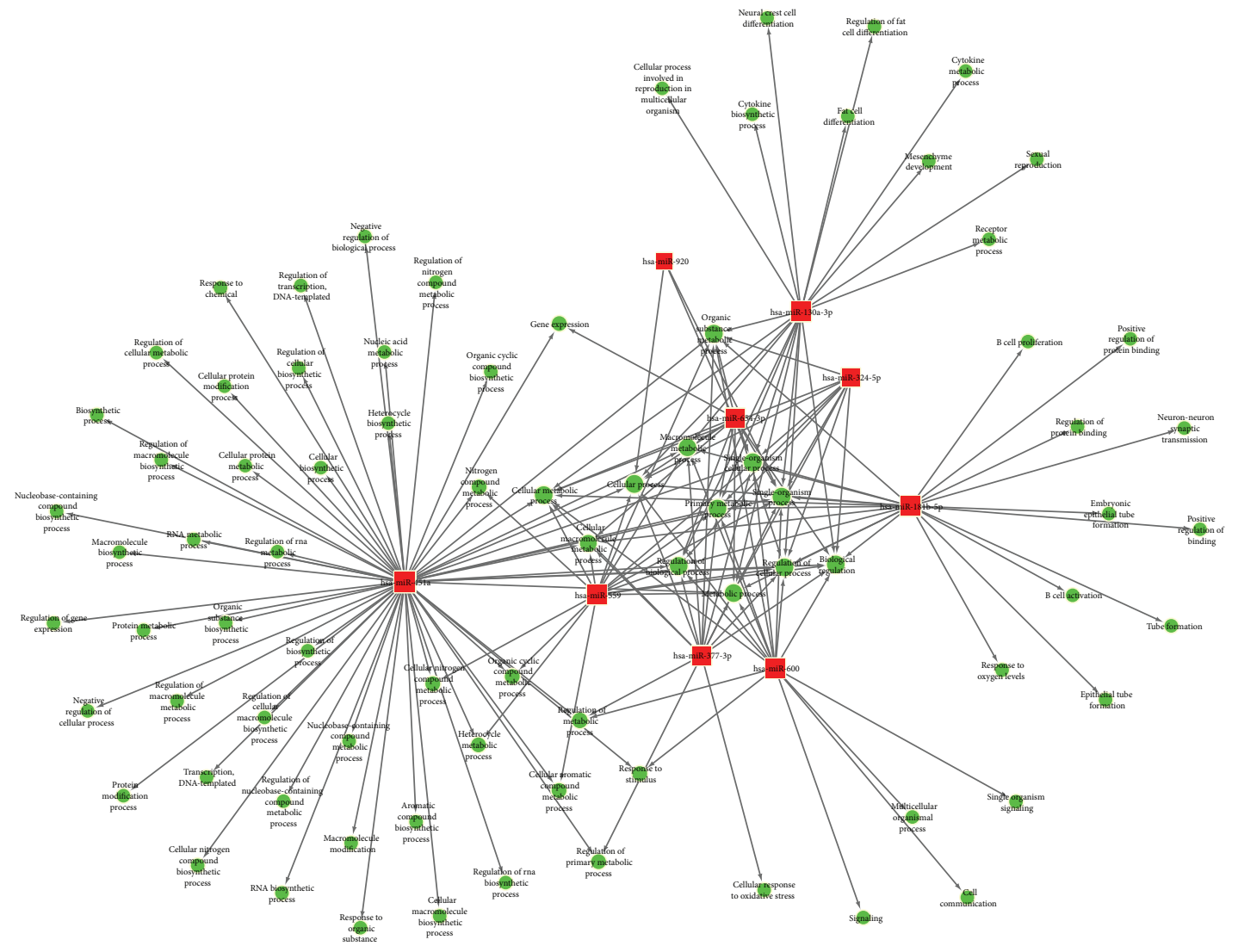

(b)

Figure 6: Continued. 


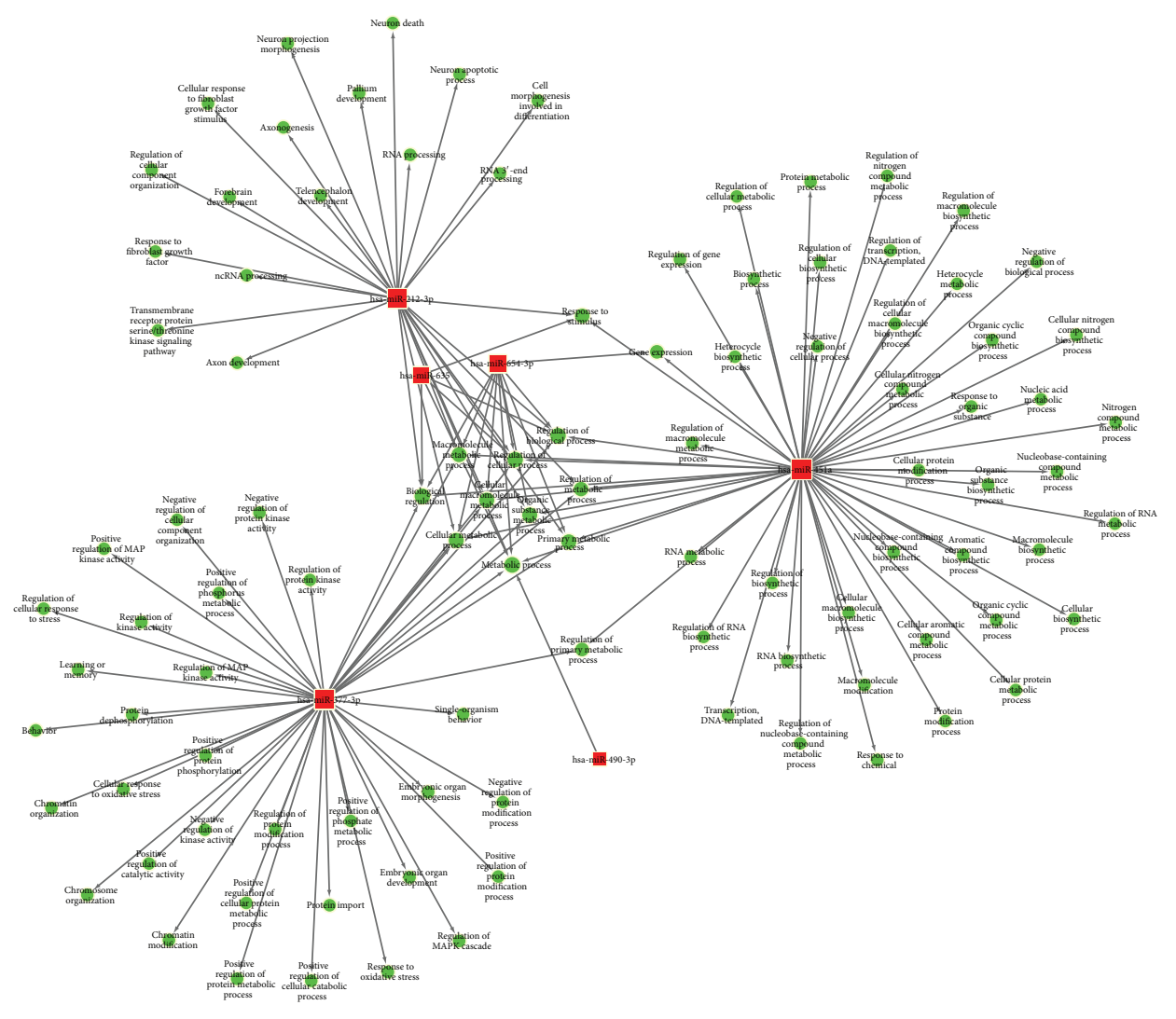

(c)

FIGURE 6: miRNA-GO networks based on the identified GO terms of the target genes of the differentially expressed miRNAs between the ASC group and HC group (a), CHB group and HC group (b), and CHB group and ASC group (c). The red boxes represent differentially expressed miRNAs; the blue circles represent the significant GO terms; and the straight lines represent interactions between the miRNA and the GO term. GO, gene ontology; miRNA, microRNA.

2-fold difference in their expression between the CHB group and ASC group. These observations indicated that common and phase-specific mechanisms may exist at the miRNA level in ASCs and CHB patients. Thus, investigating these miRNAs and their mechanisms might be of great importance for further research into the pathogenesis of hepatitis B infection.

miRNAs are likely to play a prominent role in altering the global signaling networks and pathways involved in the progression of liver disease. Therefore, in this study, we identified the target genes of the differentially expressed miRNAs and built miRNA-gene networks to study their interactions; further, we used GO and signaling pathway analysis to determine the functions and biological pathways of the target genes. GO analysis demonstrated that the target genes were primarily involved with response to nutrient, regulation of primary metabolic process, cell part, kinase activity, and binding, and pathway enrichment showed that the target genes were involved in several important pathways, such as those related to endocytosis, ubiquitin mediated proteolysis, TGF-beta signaling pathway, and p53 signaling pathway. Finally, the significance of the identified miRNAs was determined by building miRNA-GO and miRNA-pathway networks and calculating the degree of complexity of the nodes [57]. Using this analytical approach, we identified the key miRNAs at the centre of the signal transduction network in patients with HBV infection (both carriers and those with chronic infection). Since the remaining miRNAs also had a considerable degree of complexity, they will be the subject of our future studies. Meanwhile, our current results indicate that miR-142-3p, miR-181b-5p, miR-199a-3p, miR-130b-3p, miR-34a-5p, miR-301a-3p, and miR-376c-3p may be closely related to disease pathogenesis in ASCs and that miR-181b-5p, miR-130a-3p, miR-559, miR-920, miR-377-3p, miR-654-3p, miR-451a, miR-600, and miR-324-5p may play an important role in the pathogenesis of chronic hepatitis B. Further, miR212-3p, miR-490-3p, and miR-635, and especially miR-377$3 p$, miR-654-3p, and miR-451a, may be associated with the progression of hepatitis B-related diseases, as they were found to be significant in both ASCs and CHB patients. Several of these miRNAs have already been reported in previous studies, namely, miR-181b-5p, miR-199a-3p, miR-130b-3p, miR-34a5p, miR-301a-3p, miR-130a-3p, miR-654-3p, miR-451a, miR377-3p, and miR-600. However, miR-142-3p, miR-376c-3p, miR-559, miR-920, miR-324-5p, miR-212-3p, miR-490-3p, and miR-635 have not been previously reported in studies on HBV-related diseases, which makes this finding novel. No significant correlation was found between the levels of miR-195-3p, miR-144-5p, miR-451a, and miR-920 and clinical 


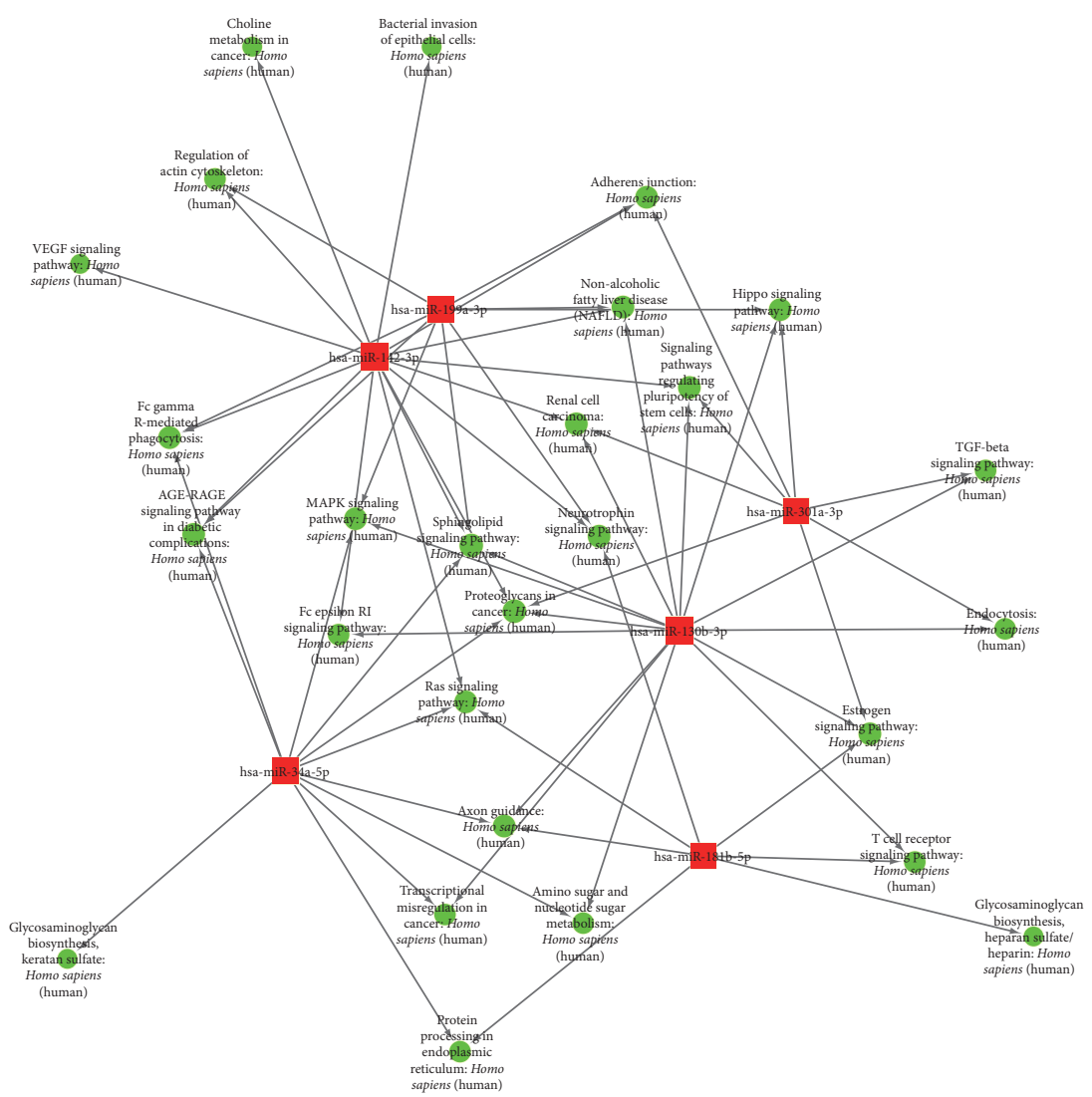

(a)

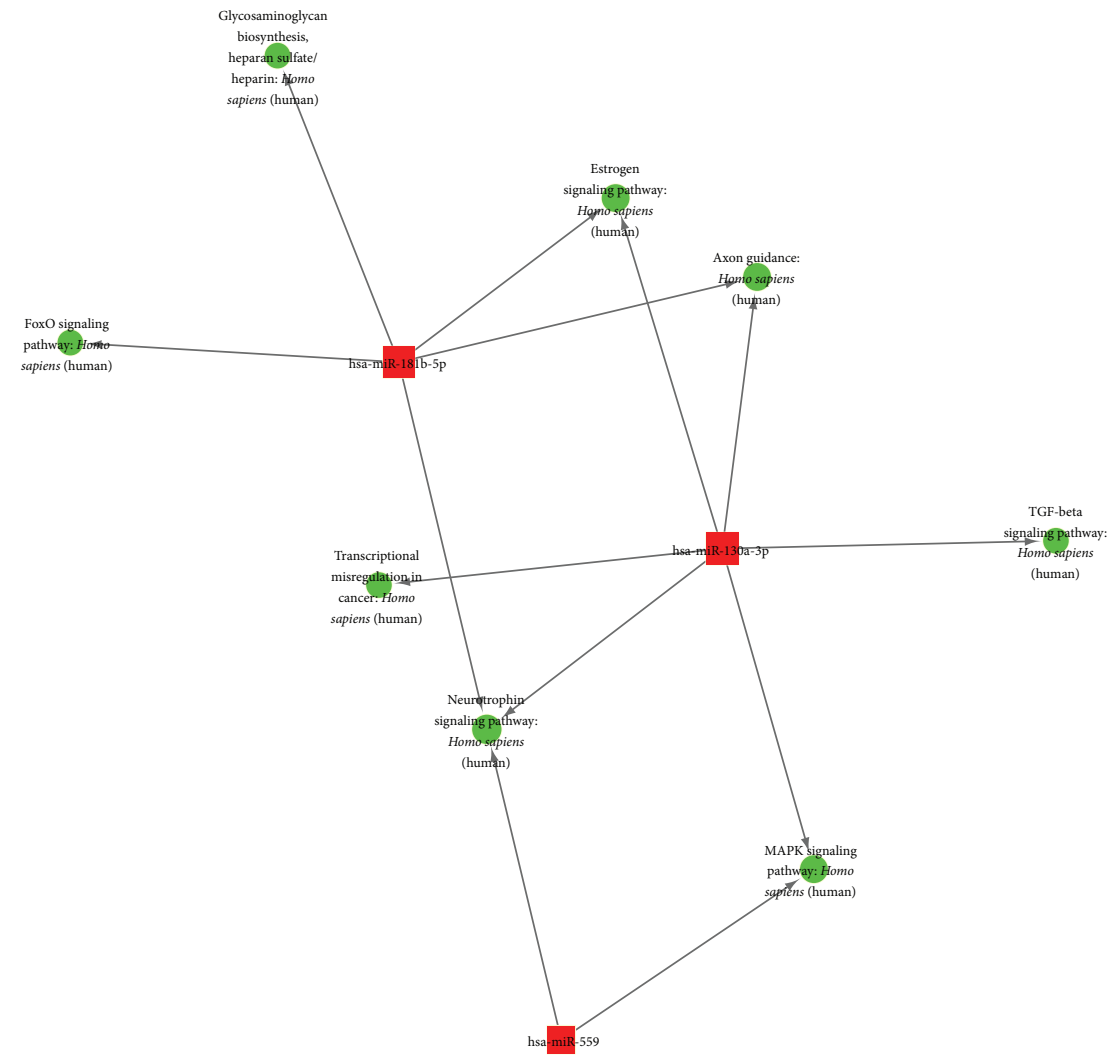

(b)

Figure 7: Continued. 


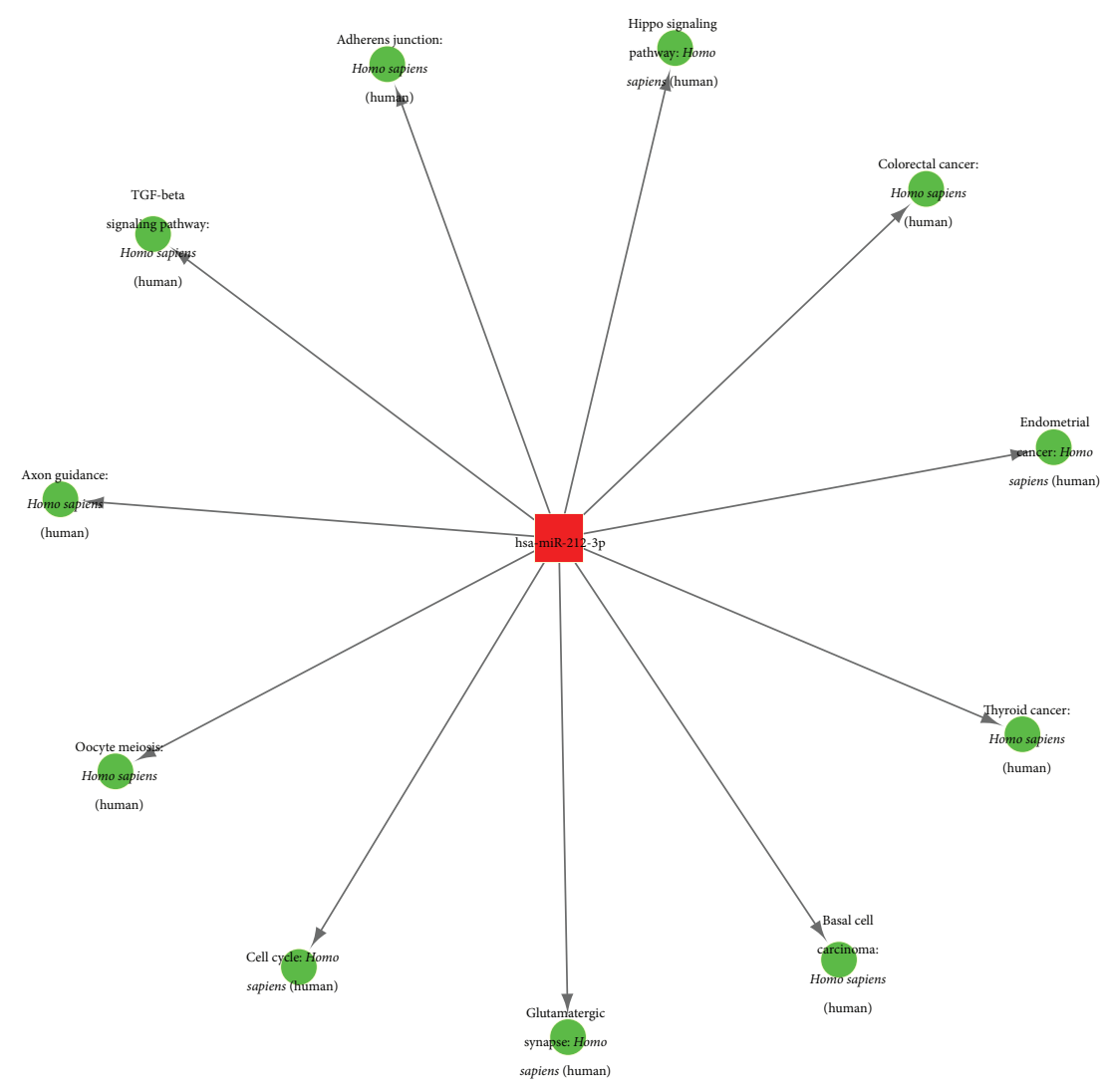

(c)

FIGURE 7: miRNA-pathway networks based on the identified pathways of the target genes of the differentially expressed miRNAs between the ASC and HC group (a), between the CHB and HC group (b), and between the CHB and ASC group (c). The red squares represent miRNAs; the blue round spots represent the pathways; and the lines represent interactions between the miRNAs and their target gene pathways.

TABLE 5: Correlation of miRNAs and clinical indicators of HBV infection.

\begin{tabular}{|c|c|c|c|}
\hline MicroRNA & Relevance & Clinical indicators & Citation \\
\hline \multirow{3}{*}{ miR-122 } & Positive correlation & HBV DNA & [16] \\
\hline & Positive correlation & ALT levels & {$[17]$} \\
\hline & Positive correlation & HBsAg levels, ALT levels, and HBV DNA titers & {$[18]$} \\
\hline $\operatorname{miR}-22$ & Positive correlation & HBsAg levels, ALT levels & {$[18]$} \\
\hline \multirow{2}{*}{$\operatorname{miR}-29$} & Positive correlation & HBV DNA & {$[16]$} \\
\hline & Negatively correlated & Liver fibrotic stages and necroinflammation grades & [19] \\
\hline miR-210 & Positive correlation & HBV DNA, HBs antigen, alanine aminotransferase (ALT), and HAI score & [20] \\
\hline miR-33a & Positive correlation & Hepatic fibrosis & {$[21]$} \\
\hline $\operatorname{miR}-125 b$ & Negatively correlated & HBV DNA intermediates and secretion of $\mathrm{HBsAg}$ and $\mathrm{HBeAg}$ & {$[22]$} \\
\hline \multirow{2}{*}{ miR-146a } & Positive correlation & HBsAg levels & {$[23]$} \\
\hline & Positive correlation & ALT & {$[14]$} \\
\hline miR-548ah-5p & Negative correlation & HBV DNA & [14] \\
\hline
\end{tabular}

indicators of HBV infection. It is likely due to the small sample size of this study and clinical information missed in some patients. Taking the correlated between miR-144-5p, miR-45la, and ALT as an example, it was possible that the association was real; with a larger sample, we might find that the association did become statistically significant. In attempts to answer these questions, we summarized miRNAs that was reported as a strong correlation with clinical indicators of HBV infection (Table 5).

The functions of the previously reported miRNAs are described here. Previous studies have demonstrated that miRNA-181a is a critical player in the modulation of both 
TABLE 6: Deregulated miRNA in HBV infection or HBV-related disease.

\begin{tabular}{|c|c|c|c|}
\hline MicroRNA & Alteration & Target & Citation \\
\hline miR-1 & Up & HDAC4, FXRA & [25] \\
\hline miR-15a & Down & HBp and HBx & [26] \\
\hline miR-15b & $\begin{array}{c}\text { Down (early } \\
\text { stage) } \\
\text { Up (late stage) }\end{array}$ & HNF1 $\alpha$ & {$[27]$} \\
\hline $\mathrm{miR}-15 \mathrm{a} / 16$ & Down & Bcl-2 & [28] \\
\hline miR-17 & Up & ULK1, ATG7, p62 & [29] \\
\hline miR-17-92 cluster & Up & HBV transcripts, E2F1 & {$[30,31]$} \\
\hline miR-18a & Up & ESR1, ERa & {$[29,32]$} \\
\hline miR-19b & Up & P53 & {$[30]$} \\
\hline miR-20a & Up & Egln3/PHD3 & {$[30]$} \\
\hline miR-21 & Up & PDCD4, PTEN & {$[33]$} \\
\hline miR-22 & Down & CDKN1A, AKT3, p21 & {$[34,35]$} \\
\hline miR-26b & Down & CHORDC1 & {$[36]$} \\
\hline miR-27a & Up & MAP2K4, TR $\beta 1$ & {$[30]$} \\
\hline miR-29a & Up & PTEN & {$[37]$} \\
\hline $\operatorname{miR}-29 c$ & Down & TNFAIP3 & {$[38]$} \\
\hline miR-33a & Up & Smad7 & {$[21]$} \\
\hline $\operatorname{miR}-34 c$ & Down & TGIF2 & {$[39]$} \\
\hline miR-93 & Down & MICA & {$[40]$} \\
\hline miR-99a & Down & $\mathrm{AGO} 2$ & {$[41]$} \\
\hline miR-101 & Down & FOXO1, EZH2, DNMT3A & {$[42-44]$} \\
\hline miR-103 & Up & PER3, CDK5R1 & {$[29]$} \\
\hline miR-106a & Up & P130, FAS & {$[29]$} \\
\hline miR-107 & Up & CDK8, let-7 & {$[29]$} \\
\hline miR-122 & Down & HBV DNA polymerase, Cyclin G1, HO-1, NDRG3, PPAR $\gamma$, PBF & [45-47] \\
\hline miR-125a-5p & $\mathrm{Up}$ & HBsAg & {$[46,48]$} \\
\hline $\operatorname{miR}-125 b$ & Down & SCNN1A & [22] \\
\hline miR-125b-5p & Up & HBsAg, LIN28B/let-7 axis & {$[49,50]$} \\
\hline $\operatorname{miR}-126$ & Down & PI3KR2, Crk, PLK2 & {$[30]$} \\
\hline miR-130a & Down & PPARG, Era, PGCl $\alpha$, PPAR $\gamma$ & {$[30,45,51]$} \\
\hline miR-141 & - & $\operatorname{PPAR} \alpha$ & {$[46]$} \\
\hline miR-143 & Up & FNDC3B & {$[47]$} \\
\hline miR-145 & Down & CUL5 & {$[52]$} \\
\hline miR-146a & Up & STAT1, CFH, RIG-I, RIG-G & {$[23,46,53]$} \\
\hline miR-148a & Up & c-Met, Wnt & {$[30]$} \\
\hline miR-152 & Down & DNMT1 & {$[46]$} \\
\hline miR-155 & Up & C/EBP, SOCS1 & {$[46]$} \\
\hline miR-181a & Up & HLA-A, E2F5 & {$[46,47]$} \\
\hline miR-199a & Up & HBsAg & {$[46]$} \\
\hline miR-205 & Down & $\mathrm{HBx}$ & {$[46]$} \\
\hline $\operatorname{miR}-210$ & Up & HBV pre-S1 & {$[46]$} \\
\hline miR-221 & Up & PI3-K/Akt & [29] \\
\hline miR-224 & Up & HOXD10, CDC42, Smad4 & {$[29,47]$} \\
\hline miR-331-3p & Up & ING5 & {$[54]$} \\
\hline $\operatorname{miR}-370$ & Down & NFIA & {$[45]$} \\
\hline $\operatorname{miR}-372 / 373$ & Up & NFIB & [46] \\
\hline $\operatorname{miR}-429$ & Down & NOTCH1 & {$[55]$} \\
\hline miR-449a & Up & CREBFXRA & {$[45]$} \\
\hline
\end{tabular}


TABLE 6: Continued.

\begin{tabular}{lccc}
\hline MicroRNA & Alteration & Target & Citation \\
\hline miR-501 & Up & HBXIP & [46] \\
miR-545/374a & Up & ESRRG & [NF $\gamma$ R1 \\
miR-548ah & Up & Dicer, EDEM1 & [46] \\
miR-581 & Down & RASSF1A & [46] \\
miR-602 & Down & CEBPA & [29] \\
miR-939 & Down & HBcAg & [45] \\
miR-1231 & Up & PD-1 & [46] \\
miR-4717 & Down & CCR7 & [29] \\
Let-7a & Down & & \\
\hline
\end{tabular}

innate [58] and adaptive [59] immunity and is involved in distinct pathological processes. miR-199a-3p has been reported to bind to and directly suppress HBV RNA [60]. miR-130a and miR-130b share the same seed sequences, and miRNA-130a can inhibit hepatitis B virus replication by targeting PGCl $\alpha$ and PPAR $\gamma$ [51]. Moreover, downregulation of miR-377 contributes to IRX3 deregulation in hepatocellular carcinoma [61]. miRNA-34is associated with hepatic fat metabolism [62]. A recent study has shown that the expression of miR-301 in the serum was significantly higher in HCC patients than in healthy subjects [63]. Finally, hasmiR-600 was found to be associated with inflammatory and cell cycle pathways [12]. In general, miRNAs could act as a cellular anti-viral defense, as siRNAs do in plants and lower eukaryotes, or cellular miRNAs could be exploited by the virus to help establish a favorable environment for its replication and survival. As shown in Table 6, we summarized miRNAs that was reported as a dysregulated miRNA by HBV infection.

In summary, we have comprehensively analyzed the cellular miRNA profiles of HBV-infected carriers and chronic disease patients. We have identified certain important miRNAs that were differentially expressed in the patients and were also differentially expressed between the carriers and chronic disease patients. Further, network biology analysis of the target genes of these miRNAs demonstrated the global regulation of signaling network pathways by these miRNAs. Further studies on the molecular regulating mechanisms of miRNAs in HBV-related diseases need to be conducted to further elucidate the pathogenesis of chronic hepatitis $B$ and identify therapeutic targets for treatment.

\section{Conflicts of Interest}

The authors have stated explicitly that there are no conflicts of interest in connection with this article.

\section{Authors' Contributions}

Hongyan Diao and Xianliang Hou conceived, designed, and performed most of the experiments with significant contributions from Yan Liang, Jianing Chen, Yingfeng Wei, Ping Zeng, Lin Wang, and Chong Lu; Yan Liang, Yingfeng Wei, and Chong Lu contributed to sample collection; Xianliang Hou, Jianing Chen, Lin Wang, and Ping Zeng analyzed the data; Hongyan Diao and Xianliang Hou wrote the paper. All authors provided final approval and agree to be accountable for all aspects of the work.

\section{Acknowledgments}

This work was supported by the National Natural Science Foundation of China (nos. 81271810, 81571953), the National Basic Research Program (2013CB531405), Zhejiang Provincial Natural Science Foundation of China (LY16H190002), and Zhejiang Medical Science and Technology Project (2015118507).

\section{References}

[1] C. Seeger and W. S. Mason, "Hepatitis B virus biology," Microbiology and Molecular Biology Reviews, vol. 64, no. 1, pp. 51-68, 2000.

[2] Y. W. Huang, K. Chayama, J. H. Kao, and S. S. Yang, "Detectability and clinical significance of serum hepatitis B virus ribonucleic acid," Hepatobiliary Surgery and Nutrition, vol. 4, no. 3, pp. 197-202, 2015.

[3] S. J. Hadziyannis and G. V. Papatheodoridis, "Hepatitis B e antigen-negative chronic hepatitis B: Natural history and treatment," Seminars in Liver Disease, vol. 26, no. 2, pp. 130-141, 2006.

[4] S. Maimone, G. Caccamo, G. Squadrito et al., "A combination of different diagnostic tools allows identification of inactive hepatitis B virus carriers at a single time point evaluation," Liver International, vol. 37, no. 3, pp. 362-368, 2017.

[5] B. P. Lewis, C. B. Burge, and D. P. Bartel, "Conserved seed pairing, often flanked by adenosines, indicates that thousands of human genes are microRNA targets," Cell, vol. 120, no. 1, pp. 15-20, 2005.

[6] C. L. Jopling, M. Yi, A. M. Lancaster, S. M. Lemon, and P. Sarnow, "Molecular biology: modulation of hepatitis $\mathrm{C}$ virus RNA abundance by a liver-specific MicroRNA," Science, vol. 309, no. 5740, pp. 1577-1581, 2005.

[7] X. Zhang, C. Chen, M. Wu et al., "Plasma microRNA profile as a predictor of early virological response to interferon treatment in chronic hepatitis B patients," Antiviral Therapy, vol. 17, no. 7, pp. 1243-1253, 2012. 
[8] Y. Murakami, H. Toyoda, T. Tanahashi et al., "Comprehensive miRNA expression analysis in peripheral blood can diagnose liver disease," PLoS ONE, vol. 7, no. 10, Article ID e48366, 2012.

[9] Y. Chen, L. Li, Z. Zhou, N. Wang, C.-Y. Zhang, and K. Zen, "A pilot study of serum microRNA signatures as a novel biomarker for occult hepatitis B virus infection," Medical Microbiology and Immunology, vol. 201, no. 3, pp. 389-395, 2012.

[10] H. Zhang, Q. Y. Li, Z. Z. Guo et al., "Serum levels of mi-croRNAs can specifically predict liver injury of chronic hepatitis B," World Journal of Gastroenterology, vol. 18, no. 37, pp. 5188-5196, 2012.

[11] A. S. F. Lok and B. J. McMahon, "Chronic hepatitis B," Hepatology, vol. 45, no. 2, pp. 507-539, 2007.

[12] X.-B. Pan, H. Ma, Q. Jin, and L. Wei, "Characterization of microRNA expression profiles associated with hepatitis B virus replication and clearance in vivo and in vitro," Journal of Gastroenterology and Hepatology, vol. 27, no. 4, pp. 805-812, 2012.

[13] C.-J. Guo, Q. Pan, D.-G. Li, H. Sun, and B.-W. Liu, "miR-15b and miR-16 are implicated in activation of the rat hepatic stellate cell: an essential role for apoptosis," Journal of Hepatology, vol. 50, no. 4, pp. 766-778, 2009.

[14] T. Xing, H. Xu, W. Yu, B. Wang, and J. Zhang, "Expression profile and clinical significance of miRNAs at different stages of chronic hepatitis B virus infection," International Journal of Clinical and Experimental Medicine, vol. 8, no. 4, pp. 5611-5620, 2015.

[15] Y.-F. Pan, T. Qin, L. Feng, and Z.-J. Yu, "Expression profile of altered long non-coding RNAs in patients with HBV-associated hepatocellular carcinoma," Journal of Huazhong University of Science and Technology-Medical Science, vol. 33, no. 1, pp. 96101, 2013.

[16] T. J. Xing, D. F. Jiang, J. X. Huang, and Z. L. Xu, "Expression and clinical significance of miR-122 and miR-29 in hepatitis B virusrelated liver disease," Genetics and Molecular Research, vol. 13, no. 3, pp. 7912-7918, 2014.

[17] O. Waidmann, V. Bihrer, T. Pleli et al., "Serum microRNA-122 levels in different groups of patients with chronic hepatitis B virus infection," Journal of Viral Hepatitis, vol. 19, no. 2, pp. e58e65, 2012.

[18] K. Arataki, C. N. Hayes, S. Akamatsu et al., "Circulating microRNA-22 correlates with microRNA-122 and represents viral replication and liver injury in patients with chronic hepatitis B," Journal of Medical Virology, vol. 85, no. 5, pp. 789798, 2013.

[19] C. Huang, J. M. Zheng, Q. Cheng et al., "Serum microRNA-29 levels correlate with disease progression in patients with chronic hepatitis B virus infection," Journal of Digestive Diseases, vol. 15, no. 11, pp. 614-621, 2014.

[20] F. Yu, J. Yang, J. Ouyang et al., "Serum microRNA-210 levels in different groups of chronic hepatitis B patients," Clinica Chimica Acta, vol. 450, pp. 203-209, 2015.

[21] C.-F. Huang, C.-C. Sun, F. Zhao, Y.-D. Zhang, and D.-J. Li, "miR33a levels in hepatic and serum after chronic HBV-induced fibrosis," Journal of Gastroenterology, vol. 50, no. 4, pp. 480-490, 2015.

[22] Z. Zhang, J. Chen, Y. He et al., "miR-125b inhibits hepatitis $B$ virus expression in vitro through targeting of the SCNN1A gene," Archives of Virology, vol. 159, no. 12, pp. 3335-3343, 2014.

[23] Z. Hou, J. Zhang, Q. Han et al., "Hepatitis B virus inhibits intrinsic RIG-I and RIG-G immune signaling via inducing miR146a," Scientific Reports, vol. 6, Article ID 26150, 2016.
[24] Y. Sun, S. Shen, H. Tang et al., "MiR-429 identified by dynamic transcriptome analysis is a new candidate biomarker for colorectal cancer prognosis," OMICS A Journal of Integrative Biology, vol. 18, no. 1, pp. 54-64, 2014.

[25] X. Zhang, E. Zhang, Z. Ma et al., "Modulation of hepatitis B virus replication and hepatocyte differentiation by MicroRNA1," Hepatology, vol. 53, no. 5, pp. 1476-1485, 2011.

[26] Y. Wang, L. Jiang, X. Ji, B. Yang, Y. Zhang, and X.-D. Fu, "Hepatitis B viral RNA directly mediates down-regulation of the tumor suppressor microRNA miR-15a/miR-16-1 in hepatocytes," Journal of Biological Chemistry, vol. 288, no. 25, pp. 18484-18493, 2013.

[27] X. Dai, W. Zhang, H. Zhang et al., "Modulation of HBV replication by microRNA-15b through targeting hepatocyte nuclear factor $1 \alpha$," Nucleic Acids Research, vol. 42, no. 10, pp. 6578-6590, 2014.

[28] N. Liu, J. Zhang, T. Jiao et al., "Hepatitis B virus inhibits apoptosis of hepatoma cells by sponging the MicroRNA 15a/16 cluster," Journal of Virology, vol. 87, no. 24, pp. 13370-13378, 2013.

[29] E. Petrini, G. P. Caviglia, M. L. Abate, S. Fagoonee, A. Smedile, and R. Pellicano, "microRNA in HBV-related hepatocellular carcinoma: functions and potential cinical applications," Panminerva Medica, vol. 57, no. 4, pp. 201-209, 2015.

[30] E. Connolly, M. Melegari, and P. Landgraf, "Elevated expression of the miR-17-92 polycistron and miR-21 in hepadnavirusassociated hepatocellular carcinoma contributes to the malignant phenotype," The American Journal of Pathology, vol. 173, no. 3, pp. 856-864, 2008.

[31] Y. J. Jung, J.-W. Kim, S. J. Park et al., “c-Myc-mediated overexpression of miR-17-92 suppresses replication of hepatitis $B$ virus in human hepatoma cells," Journal of Medical Virology, vol. 85, no. 6, pp. 969-978, 2013.

[32] W.-H. Liu, S.-H. Yeh, C.-C. Lu et al., "MicroRNA-18a prevents estrogen receptor-alpha expression, promoting proliferation of hepatocellular carcinoma cells," Gastroenterology, vol. 136, no. 2, pp. 683-693, 2009.

[33] P. Damania, B. Sen, S. B. Dar et al., "Hepatitis B virus induces cell proliferation via $\mathrm{HBx}$-induced microRNA-21 in hepatocellular carcinoma by targeting Programmed Cell Death Protein4 (PDCD4) and Phosphatase and Tensin Homologue (PTEN)," PLoS ONE, vol. 9, no. 3, Article ID e91745, 2014.

[34] C. Shi and X. Xu, "MicroRNA-22 is down-regulated in hepatitis B virus-related hepatocellular carcinoma," Biomedicine and Pharmacotherapy, vol. 67, no. 5, pp. 375-380, 2013.

[35] Y. Zheng and Z. Xu, "MicroRNA-22 induces endothelial progenitor cell senescence by targeting AKT3," Cellular Physiology and Biochemistry, vol. 34, no. 5, pp. 1547-1555, 2014.

[36] F. Zhao, G. Xu, Y. Zhou et al., "MicroRNA-26b inhibits hepatitis $B$ virus transcription and replication by targeting the host factor CHORDC1 protein," Journal of Biological Chemistry, vol. 289, no. 50, pp. 35029-35041, 2014.

[37] G. Kong, J. Zhang, S. Zhang, C. Shan, L. Ye, and X. Zhang, "Upregulated microRNA-29a by hepatitis B virus X protein enhances hepatoma cell migration by targeting PTEN in cell culture model," PLoS ONE, vol. 6, no. 5, Article ID e19518, 2011.

[38] C.-M. Wang, Y. Wang, C.-G. Fan et al., "MiR-29c targets TNFAIP3, inhibits cell proliferation and induces apoptosis in hepatitis B virus-related hepatocellular carcinoma," Biochemical and Biophysical Research Communications, vol. 411, no. 3, pp. 586-592, 2011.

[39] Y. Wang, C.-M. Wang, Z.-Z. Jiang et al., "MicroRNA-34c targets TGFB-induced factor homeobox 2,represses cell proliferation 
and induces apoptosis in hepatitis B virus-related hepatocellular carcinoma," Oncology Letters, vol. 10, no. 5, pp. 3095-3102, 2015.

[40] M. Ohno, M. Otsuka, T. Kishikawa et al., "Specific delivery of microRNA93 into HBV-replicating hepatocytes downregulates protein expression of liver cancer susceptible gene MICA," Oncotarget, vol. 5, no. 14, pp. 5581-5590, 2014.

[41] J. Zhang, H. Jin, H. Liu et al., "MiRNA-99a directly regulates AGO2 through translational repression in hepatocellular carcinoma," Oncogenesis, vol. 3, no. 4, article no. e97, 2014.

[42] Y. Wang and H. Tian, "miR-101 suppresses HBV replication and expression by targeting FOXO1 in hepatoma carcinoma cell lines," Biochemical and Biophysical Research Communications, vol. 487, no. 1, pp. 167-172, 2017.

[43] L. Xu, S. Beckebaum, S. Iacob et al., "MicroRNA-101 inhibits human hepatocellular carcinoma progression through EZH2 downregulation and increased cytostatic drug sensitivity," Journal of Hepatology, vol. 60, no. 3, pp. 590-598, 2014.

[44] X. Wei, T. Xiang, G. Ren et al., "MiR-101 is down-regulated by the hepatitis $\mathrm{B}$ virus $\mathrm{x}$ protein and induces aberrant DNA methylation by targeting DNA methyltransferase 3A," Cellular Signalling, vol. 25, no. 2, pp. 439-446, 2013.

[45] W. Deng and M. Lu, "The role of microRNAs in hepatocyte metabolism and hepatitis B virus replication," Virologica Sinica, vol. 31, no. 6, pp. 472-479, 2016.

[46] Y. Naito, Y. Tanaka, and T. Ochiya, "MicroRNAs and hepatitis B," Advances in Experimental Medicine and Biology, vol. 888, pp. 389-399, 2015.

[47] J. Lamontagne, L. F. Steel, and M. J. Bouchard, "Hepatitis B virus and microRNAs: Complex interactions affecting hepatitis B virus replication and hepatitis B virusassociated diseases," World Journal of Gastroenterology, vol. 21, no. 24, pp. 7375-7399, 2015.

[48] N. Mosca, F. Castiello, N. Coppola et al., "Functional interplay between hepatitis B virus X protein and human miR-125a in HBV infection," Biochemical and Biophysical Research Communications, vol. 449, no. 1, pp. 141-145, 2014.

[49] M. Ninomiya, Y. Kondo, O. Kimura et al., "The expression of MIR-125b-5p is increased in the serum of patients with chronic hepatitis B infection and inhibits the detection of hepatitis B virus surface antigen," Journal of Viral Hepatitis, vol. 23, no. 5, pp. 330-339, 2016.

[50] W. Deng, X. Zhang, Z. Ma, Y. Lin, and M. Lu, "MicroRNA-125b$5 \mathrm{p}$ mediates post-transcriptional regulation of hepatitis $\mathrm{B}$ virus replication via the LIN28B/let-7 axis," RNA Biology, pp. 1-10, 2017.

[51] J.-Y. Huang, S.-F. Chou, J.-W. Lee et al., "MicroRNA-130a can inhibit hepatitis B virus replication via targeting PGCl $\alpha$ and PPAR $\gamma$," RNA, vol. 21, no. 3, pp. 385-400, 2015.

[52] F. Gao, X. Sun, L. Wang, S. Tang, and C. Yan, "Downregulation of MicroRNA-145 caused by Hepatitis B Virus X protein promotes expression of CUL5 and contributes to pathogenesis of Hepatitis B virus-associated hepatocellular carcinoma," Cellular Physiology and Biochemistry, vol. 37, no. 4, pp. 1547-1559, 2015.

[53] J.-F. Li, X.-P. Dai, W. Zhang et al., "Upregulation of microRNA146 a by hepatitis $B$ virus $X$ protein contributes to hepatitis development by downregulating complement factor $\mathrm{H}$," mBio, vol. 6, no. 2, Article ID e02459-14, 2015.

[54] Y. Cao, J. Chen, D. Wang et al., "Upregulated in Hepatitis B virus-associated hepatocellular carcinoma cells, miR-331-3p promotes proliferation of hepatocellular carcinoma cells by targeting ING5," Oncotarget, vol. 6, no. 35, pp. 38093-38106, 2015.
[55] H. Gao and C. Liu, "miR-429 represses cell proliferation and induces apoptosis in HBV-related HCC," Biomedicine and Pharmacotherapy, vol. 68, no. 8, pp. 943-949, 2014.

[56] G. Zhang, N. Li, Z. Li et al., "MicroRNA-4717 differentially interacts with its polymorphic target in the PD1 3' untranslated region: A mechanism for regulating $\mathrm{PD}-1$ expression and function in HBV-associated liver diseases," Oncotarget, vol. 6, no. 22, pp. 18933-18944, 2015.

[57] J.-G. Joung, K.-B. Hwang, J.-W. Nam, S.-J. Kim, and B.-T. Zhang, "Discovery of microRNA-mRNA modules via populationbased probabilistic learning," Bioinformatics, vol. 23, no. 9, pp. 1141-1147, 2007.

[58] K. D. Taganov, M. P. Boldin, K. Chang, and D. Baltimore, "NF$\kappa \mathrm{B}$-dependent induction of microRNA miR-146, an inhibitor targeted to signaling proteins of innate immune responses," Proceedings of the National Academy of Sciences of the United States of America, vol. 103, no. 33, pp. 12481-12486, 2006.

[59] G. Curtale, F. Citarella, C. Carissimi et al., "An emerging player in the adaptive immune response: MicroRNA-146a is a modulator of IL-2 expression and activation-induced cell death in T lymphocytes," Blood, vol. 115, no. 2, pp. 265-273, 2010.

[60] G.-L. Zhang, Y.-X. Li, S.-Q. Zheng, M. Liu, X. Li, and H. Tang, "Suppression of hepatitis B virus replication by microRNA199a-3p and microRNA-210," Antiviral Research, vol. 88, no. 2, pp. 169-175, 2010.

[61] P. Wang, C. Zhuang, D. Huang, and K. Xu, "Downregulation of miR-377 contributes to IRX3 deregulation in hepatocellular carcinoma," Oncology Reports, vol. 36, no. 1, pp. 247-252, 2016.

[62] G. Szabo and S. Bala, "MicroRNAs in liver disease," Nature Reviews Gastroenterology \& Hepatology, vol. 10, no. 11, pp. 542552, 2013.

[63] L. Gramantieri, F. Fornari, E. Callegari et al., "MicroRNA involvement in hepatocellular carcinoma," Journal of Cellular and Molecular Medicine, vol. 12, no. 6, pp. 2189-2204, 2008. 


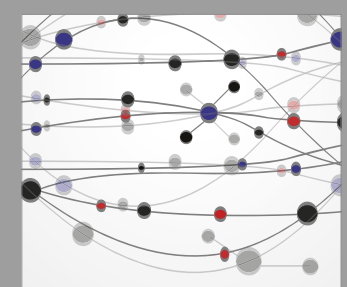

The Scientific World Journal
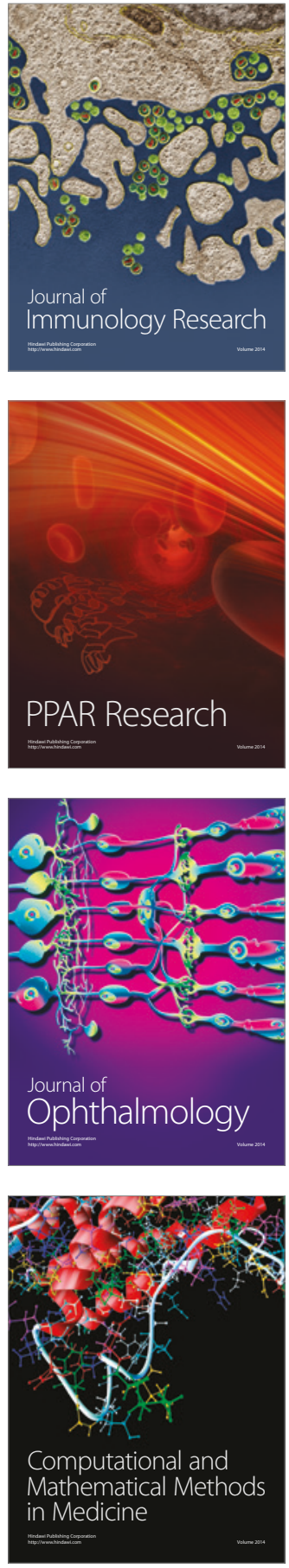

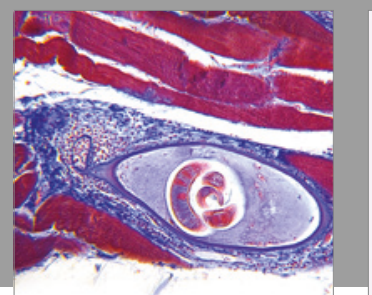

Gastroenterology Research and Practice
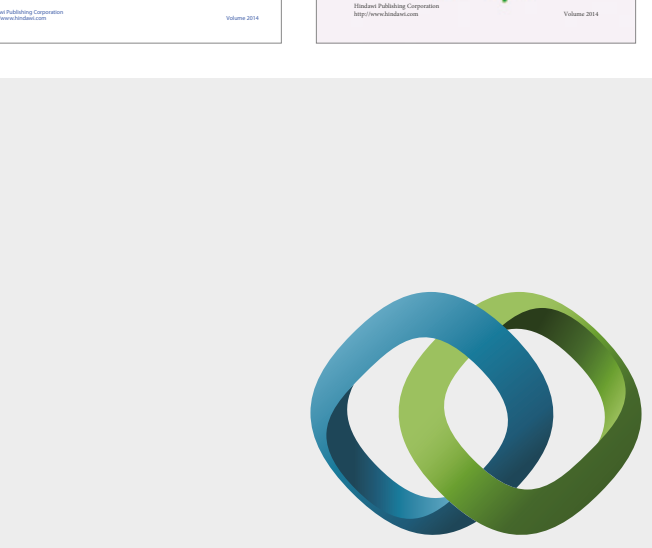

\section{Hindawi}

Submit your manuscripts at

https://www.hindawi.com
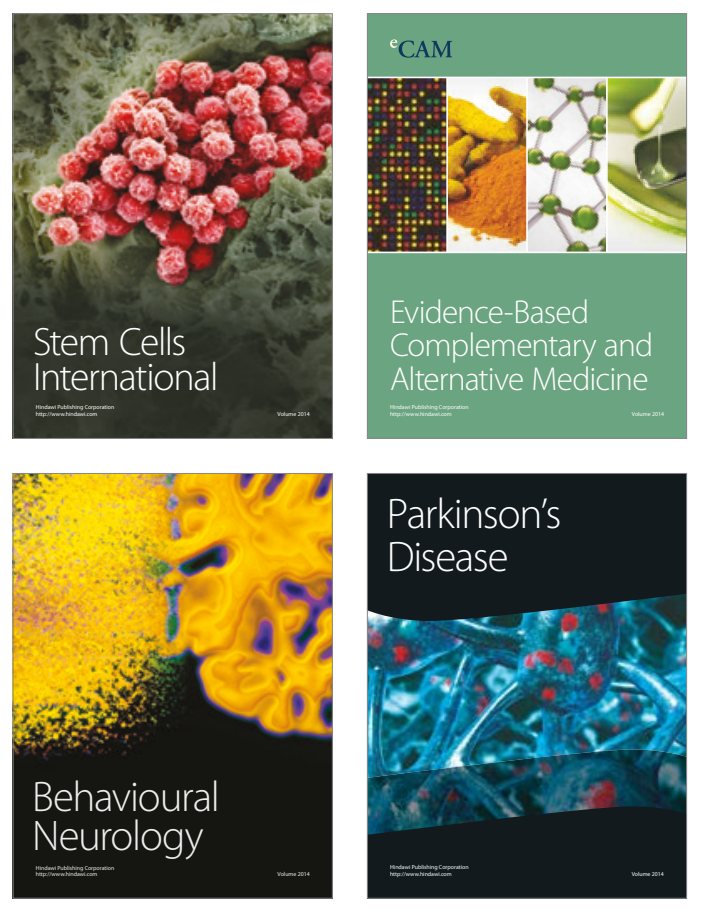
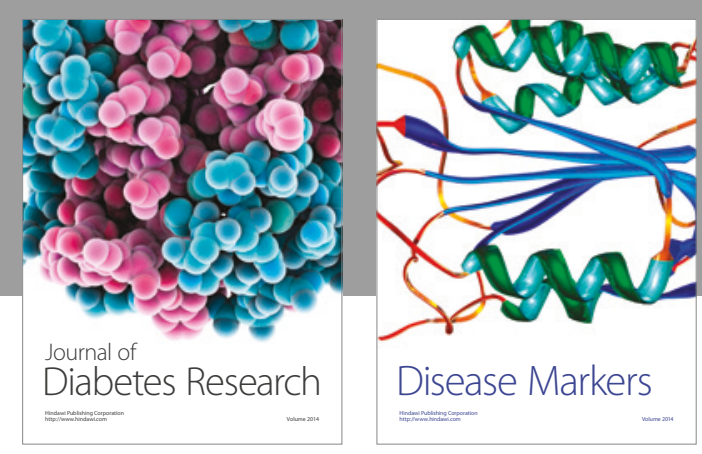

Disease Markers
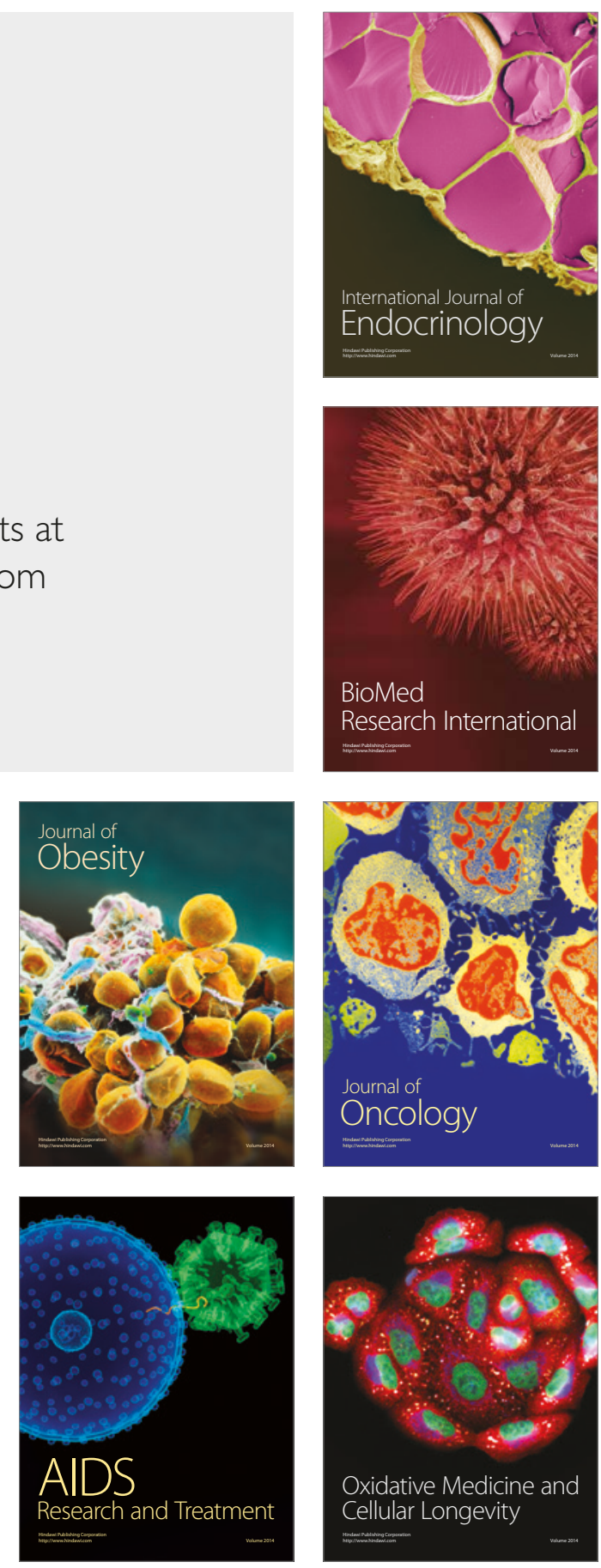